\title{
əInfluence of Wind-Induced Antenna Oscillations on Radar Observations and Its Mitigation
}

\author{
Pao-Liang Chang, Wei-Ting Fang, Pin-Fang Lin, and Yu-Shuang Tang \\ Central Weather Bureau, Taipei, Taiwan
}

(Manuscript received 29 April 2020, in final form 13 August 2020)

\begin{abstract}
As Typhoon Goni (2015) passed over Ishigaki Island, a maximum gust speed of $71 \mathrm{~m} \mathrm{~s}^{-1}$ was observed by a surface weather station. During Typhoon Goni's passage, mountaintop radar recorded antenna elevation angle oscillations, with a maximum amplitude of $\sim 0.2^{\circ}$ at an elevation angle of $0.2^{\circ}$. This oscillation phenomenon was reflected in the reflectivity and Doppler velocity fields as Typhoon Goni's eyewall encompassed Ishigaki Island. The main antenna oscillation period was approximately $0.21-0.38 \mathrm{~s}$ under an antenna rotational speed of $\sim 4 \mathrm{rpm}$. The estimated fundamental vibration period of the radar tower is approximately $0.25-0.44 \mathrm{~s}$, which is comparable to the predominant antenna oscillation period and agrees with the expected wind-induced vibrations of buildings. The reflectivity field at the $0.2^{\circ}$ elevation angle exhibited a phase shift signature and a negative correlation of -0.5 with the antenna oscillation, associated with the negative vertical gradient of reflectivity. FFT analysis revealed two antenna oscillation periods at $0955-1205$ and 1335-1445 UTC 23 August 2015. The oscillation phenomenon ceased between these two periods because Typhoon Goni's eye moved over the radar site. The VAD analysis-estimated wind speeds at a range of $1 \mathrm{~km}$ for these two antenna oscillation periods exceeded $45 \mathrm{~m} \mathrm{~s}^{-1}$, with a maximum value of approximately $70 \mathrm{~m} \mathrm{~s}^{-1}$. A bandpass filter QC procedure is proposed to filter out the predominant wavenumbers (between 40 and 70) for the reflectivity and Doppler velocity fields. The proposed QC procedure is indicated to be capable of mitigating the major signals resulting from antenna oscillations.
\end{abstract}

KEYWORDS: Data quality control; Radars/Radar observations

\section{Introduction}

Extremely strong winds frequently damage or destroy electric power supplies, telecommunications equipment, and radar hardware, including radomes and antennas. As an example, the Weather Surveillance Radar-1988 Doppler (WSR-88D) at Wu-Feng-San operated by the Central Weather Bureau (CWB) of Taiwan was destroyed by Typhoon Herb (1996), which produced maximum sustained surface winds of $65 \mathrm{~m} \mathrm{~s}^{-1}$ (Wu et al. 2002). In 2013, Super Typhoon Haiyan made landfall near Guiuan in the eastern-central Philippines, and the pedestal of the Guiuan radar was sheared off by 1-min sustained winds that possibly reached $91 \mathrm{~m} \mathrm{~s}^{-1}$ (Velden et al. 2017). In 2017, the WSR-88D radar operated by the National Weather Service (NWS) was destroyed by Hurricane Maria's powerful winds, with 1-min maximum sustained wind speed intensities estimated at $70 \mathrm{~m} \mathrm{~s}^{-1}$ as the hurricane moved onshore in southeastern Puerto Rico (Garcia-Rivera 2018).

Even if the radome can resist extremely strong winds, the quality of radar observations will be influenced by windinduced vibration of the radar tower (e.g., Tamura et al. 1993; Li et al. 2017). As a result, the quality of radar-derived weather monitoring and forecasting products, such as for severe weather detection (e.g., Johnson et al. 1998; Stumpf et al. 1998), radar quantitative precipitation estimation (QPE), quantitative precipitation forecast (QPF), and high-resolution

¿ Denotes content that is immediately available upon publication as open access.

Corresponding author: Pao-Liang Chang, larkdi@cwb.gov.tw radar data assimilation (e.g., Li et al. 2012; Wang et al. 2013; Osuri et al. 2015), will potentially be reduced. The natural vibration of a building or tower can be triggered by strong wind or earthquakes; the more uniform and symmetrical the form of the structure is, the more likely the structure will oscillate under windy conditions (e.g., Tamura et al. 1993; Li et al. 2017). Generally, the natural vibration period is proportional to the building height. Once buildings or towers vibrate, objects mounted on them (such as radomes) will oscillate in tandem.

The rapid intensification of Typhoon Goni (2015) was observed by the Ishigaki (ISHI) C-band Doppler radar on Ishigaki Island operated by the Japan Meteorological Agency (JMA) (Shimada et al. 2018). As Typhoon Goni passed near Ishigaki Island between 1000 coordinated universal time (UTC) and 1400 UTC 23 August 2015, the eyewall and eye moved over the radar site. At this time, the maximum wind speed estimated from the Doppler velocity at a radius of $1 \mathrm{~km}$ at a $1.1^{\circ}$ elevation angle exceeded $70 \mathrm{~m} \mathrm{~s}^{-1}$, which resulted in antenna oscillations that impacted the reflectivity and Doppler velocity fields, with an unusual oscillation pattern. In this study, the wind speed thresholds for antenna oscillations and the influences of these oscillations on radar observations are investigated and discussed. In addition, a similar oscillation phenomenon during Typhoon Haitang (2005) observed at the Hualien (RCHL) radar site in Taiwan is also investigated.

The data and methodology are described in the following section, and the characteristics of the radar reflectivity and Doppler velocity fields associated with antenna oscillations are analyzed in section 3 . The influences of antenna oscillations on radar observations are discussed 
TABLE 1. Specifications of the ISHI radar.

\begin{tabular}{|c|c|c|}
\hline Location & \multicolumn{2}{|c|}{$24.4267^{\circ} \mathrm{N}$} \\
\hline Height (m) & \multicolumn{2}{|c|}{533.5} \\
\hline Wavelength $(\mathrm{cm})$ & \multicolumn{2}{|c|}{5.61} \\
\hline \multirow[t]{2}{*}{ Polarization } & \multicolumn{2}{|c|}{ Single } \\
\hline & Surveillance mode & Doppler mode \\
\hline Range resolution $(\mathrm{km})$ & 0.5 & 0.5 \\
\hline Maximum unambiguous range $(\mathrm{km})$ & 400 & 250 \\
\hline Elevation angles $\left({ }^{\circ}\right)$ & $1 \mathrm{st}:-0.4,-0.1,0.2,0.6,1.1$ & 1st: $0.2,1.1,2.7,4.0$ \\
\hline & 2nd: $-0.4,-0.1,0.2,0.6,1.1,1.8,2.7,4.0$ & $\begin{array}{c}\text { 2nd: } 0.2,1.1,2.7,4.0,5.8,8.3,12.0 \text {, } \\
17.2,25.0\end{array}$ \\
\hline Nyquist velocity $\left(\mathrm{m} \mathrm{s}^{-1}\right)$ & 4.63 & 52.71 \\
\hline
\end{tabular}

in section 4. Finally, the conclusions are provided in section 5 .

\section{Data and methodology}

\section{a. Data}

The C-band Doppler ISHI radar on Ishigaki Island operated by the JMA is used in this study. Table 1 shows the radar parameters and scanning strategy for the ISHI radar. Two surveillance and Doppler modes with a total of 26 sweeps for 13 elevation angles are alternately operated and updated every $10 \mathrm{~min}$ for the ISHI radar (Fig. 1). To integrate more volume scans, radar data from the second Doppler $\left(D_{2}\right)$ and surveillance $\left(\mathrm{S}_{2}\right)$ modes are chosen for wind and reflectivity analyses, respectively. For convenience in these analyses, the volume scan time is set to 5 min after the onset of the first Doppler mode $\left(\mathrm{D}_{1}\right)$. Additionally, the ISHI radar is operated in dual-pulse repetition frequency (PRF) mode (Dazhang et al. 1984; Frush 1991) to extend the maximum unambiguous velocity. Although the Nyquist velocity can be extended to $52.71 \mathrm{~m} \mathrm{~s}^{-1}$ (Table 1), the Doppler velocity field would still encounter the folding problem when the wind speeds exceed

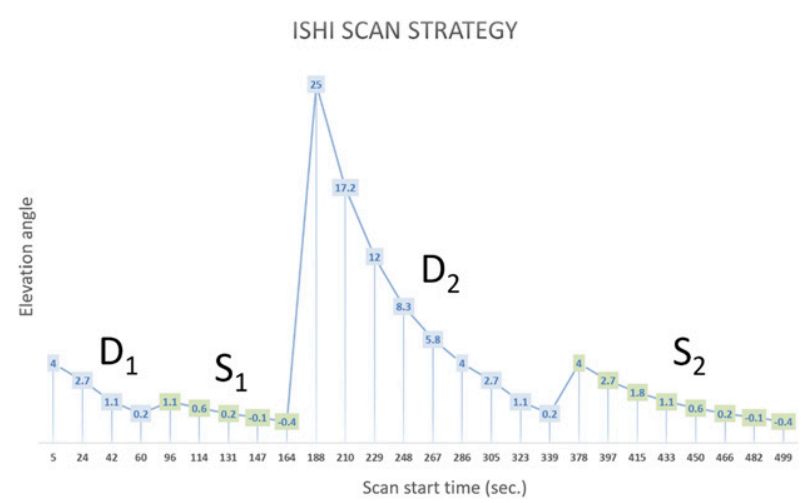

FIG. 1. Scan diagram of the elevation angles for the ISHI radar, which includes two surveillance modes (light green color, denoted $\mathrm{S}_{1}$ and $\mathrm{S}_{2}$ ) and two Doppler modes (light blue color, denoted $\mathrm{D}_{1}$ and $\mathrm{D}_{2}$ ) updated every $10 \mathrm{~min}$. The numbers on the horizontal axis indicate the seconds from the starting time. the Nyquist velocity in the inner core region of Typhoon Goni. Therefore, the vortex-based Doppler velocity dealiasing (VDVD) algorithm (Chang et al. 2019) is applied to recover the aliased Doppler velocities. In addition, data from three weather stations (IDs 94081, 94086, and 94001) within a $13-\mathrm{km}$ radius centered on the radar site are selected to investigate the spatial-temporal variations in the surface winds during Typhoon Goni's passage (Fig. 2).

\section{b. Fast Fourier transform (FFT) analyses}

Based on the recorded radar data from each beam, the angular wavenumbers (hereafter called wavenumbers) of the antenna oscillations centered on the radar site with different ranges and elevations are analyzed using the FFT algorithm (Heideman et al. 1985). Each ISHI radar plan position indicator (PPI) scan includes 512 azimuths at a resolution of approximately $0.7^{\circ}$. Therefore, one-dimensional

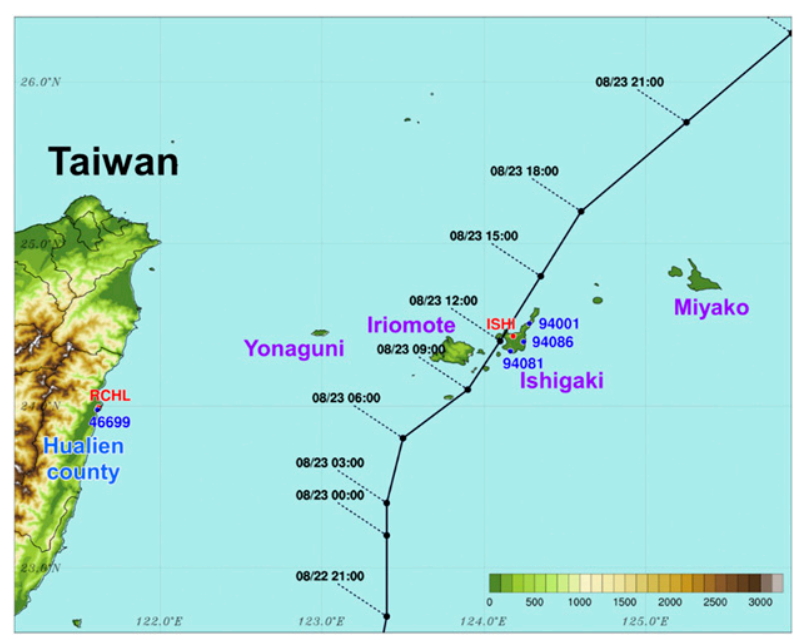

FIG. 2. Locations of the two radars (RCHL and ISHI) and four weather stations $(46699,94001,94081$, and 94086). The names of the radar stations are indicated in red text. The IDs of the weather stations are indicated in blue numbers. The black line with dates shows the CWB best track of Typhoon Goni (2015). The names of Okinawa's outer islands are indicated in purple text. 


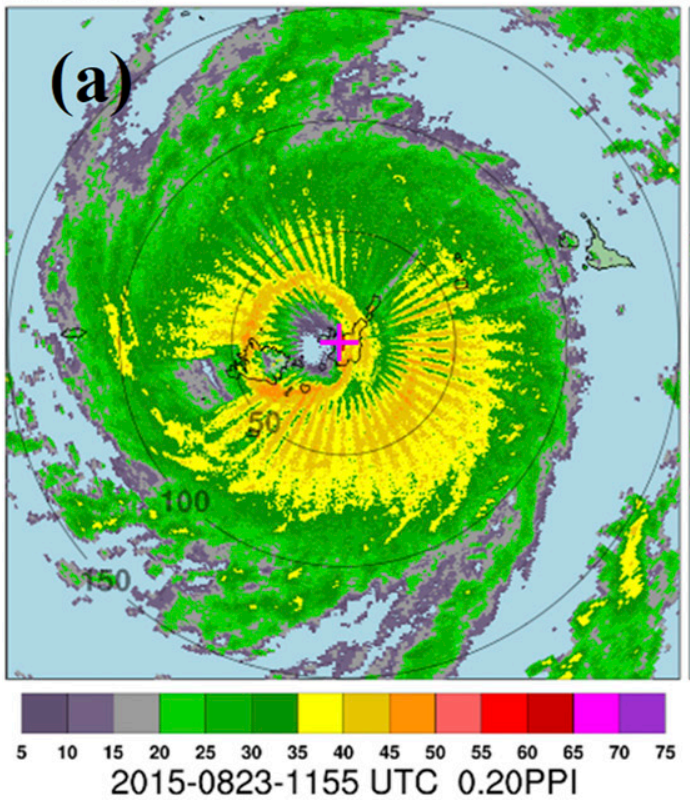

dBZ ISHI bref_raw
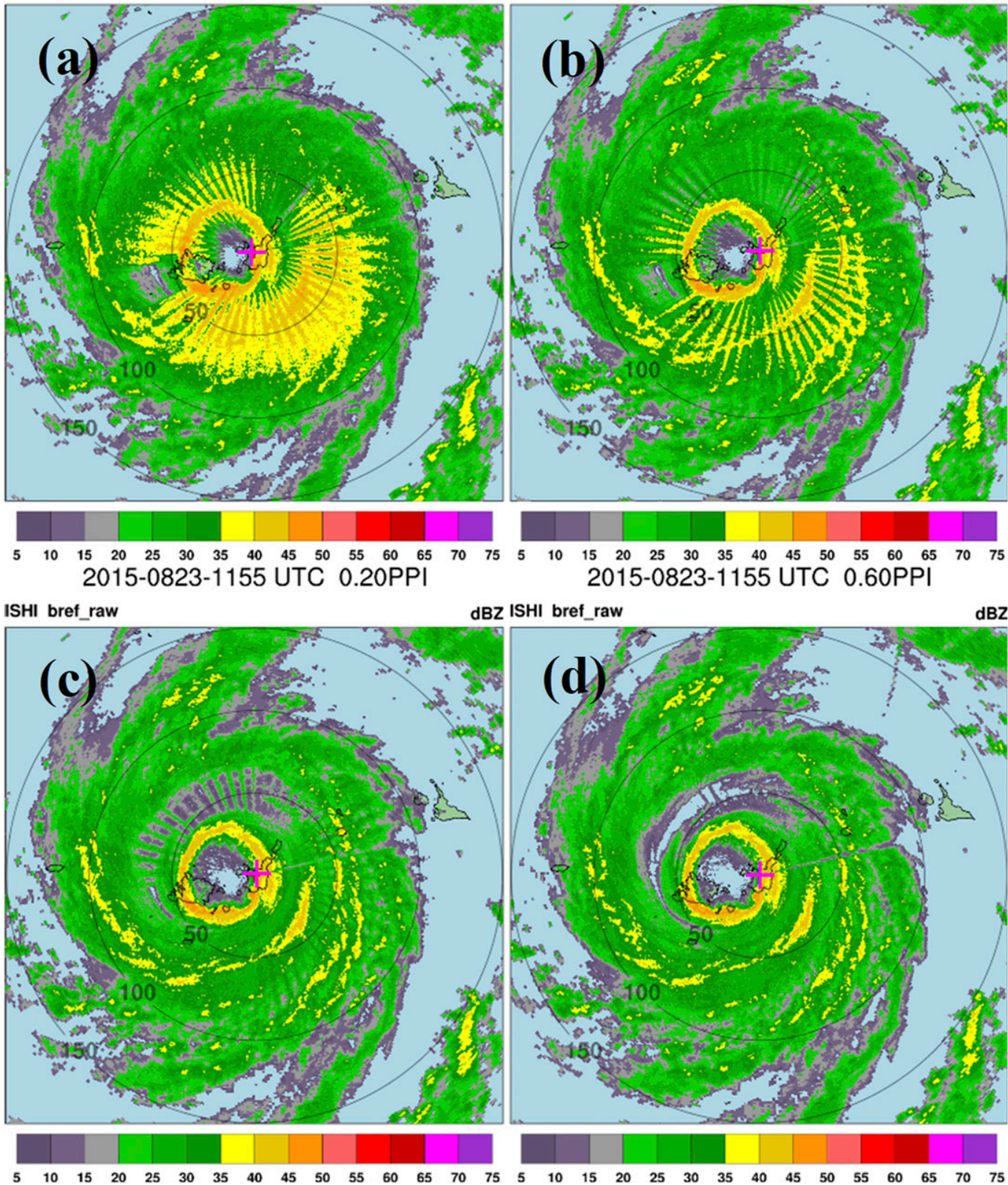

FIG. 3. Reflectivity fields at elevation angles of (a) $-0.4^{\circ}$, (b) $-0.1^{\circ}$, (c) $0.2^{\circ}$, and (d) $0.6^{\circ}$ from the ISHI radar at 1155 UTC 23 Aug 2015. The radar position is indicated by a pink cross.

spatial FFT analysis is applied to decompose the radar reflectivity and Doppler velocity data into a series of wavenumbers from 0 to 200 at a constant radius and elevation. Based on the rotational speed of the radar antenna, the predominant oscillation periods (frequencies) can be determined by selecting the wavenumbers of crucial components. Additionally, quality control (QC) procedures are performed to mitigate the effects of the oscillations based on the FFT analysis by using a bandpass filter (Warde and Torres
2017); the effects of these oscillations will be examined in section 4 .

\section{Results}

\section{a. Oscillation features}

The radar data from Typhoon Goni between 0705 and 1705 UTC 23 August 2015 are selected to investigate the influence of extremely strong winds on radar observations. 


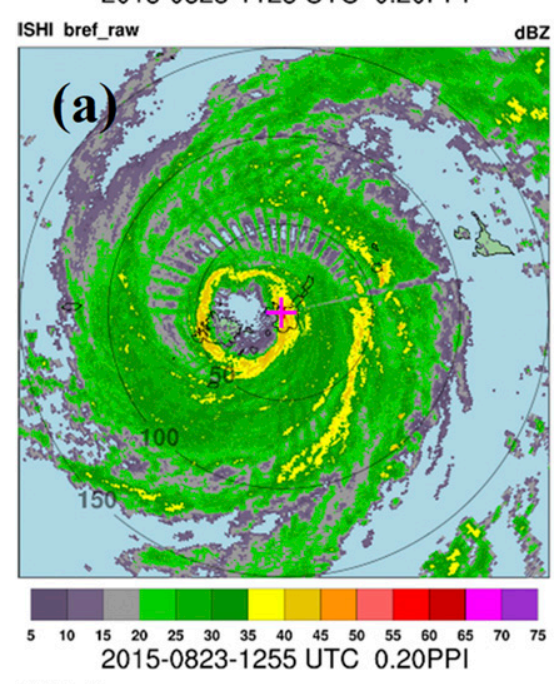
BBZ ISHI bref_raw

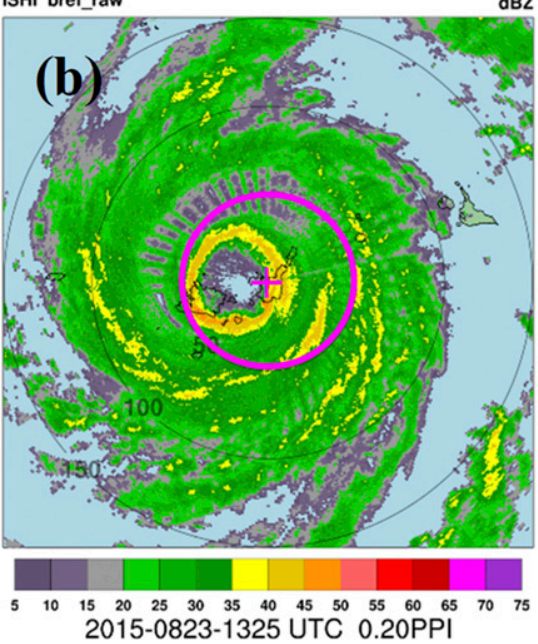
dBZ ISHI bref_raw
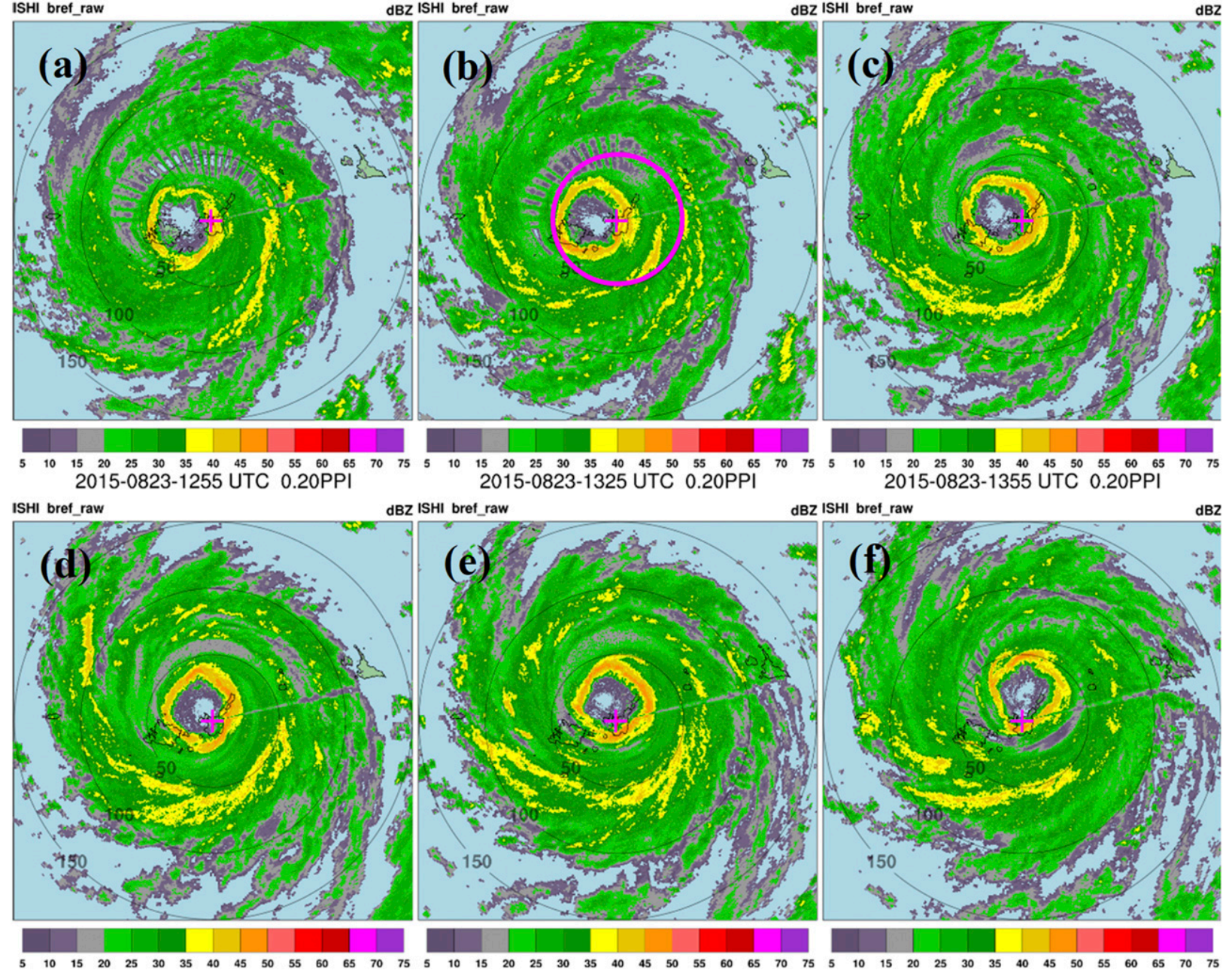

FIG. 4. (a)-(f) Temporal evolution of the reflectivity fields from the ISHI radar every $30 \mathrm{~min}$ at an elevation angle of $0.2^{\circ}$ from 1125 to 1355 UTC 23 Aug 2015. The radar position is indicated by a pink cross, and the data in the range of $50 \mathrm{~km}$ from the radar site shown in (b) with a pink ring are used for the oscillation analyses in Figs. 8 and 11.

Figure 3 shows a reflectivity example from the ISHI radar at 1155 UTC 23 August 2015. At the lowest elevation angle of $-0.4^{\circ}$, the eyewall structure is well organized with a radius of approximately $25 \mathrm{~km}$, while the eastern part of the eyewall covers the radar site. The regular radial pattern with alternating strong and weak features is very pronounced, although this periodic pattern nearly obscures the eyewall, low-reflectivity and spiral rainband regions. In addition, a band with enhanced reflectivities is found southeast of the radar site, which possibly results from sea clutter signals. At $-0.1^{\circ}$, the regular radial pattern is still pronounced, whereas the intensity of the enhanced band in the southeastern quadrant is relatively weak, but the radial oscillation pattern is still significantly similar to that at $-0.4^{\circ}$. At an elevation angle of $0.2^{\circ}$, the oscillation phenomenon is still obvious but generally weak and occurs mainly along the low-reflectivity region. This obvious oscillation phenomenon is not clearly observed at $2.7^{\circ}$, possibly because the vertical reflectivity gradients are generally weak compared with the observations at lower elevation angles. Moreover, the oscillation signals occur in limited areas around the outer rainband regions. Although the oscillation signals are more significant at an elevation angle of $-0.1^{\circ}$ than at any other elevation angle, the temporal evolution of available reflectivity (Fig. 4) and Doppler velocity (Fig. 5) observations at an elevation angle of $0.2^{\circ}$ is documented every $30 \mathrm{~min}$ from 1125 UTC to 1355 UTC during Typhoon Goni's passage near Ishigaki Island.

The regular radial pattern in the reflectivity already exists in the low-reflectivity region at 1125 UTC (Fig. 4a), at which time the oscillation phenomenon is comparable to that at 1155 UTC (Fig. 4b). Between 1225 and 1325 UTC (Figs. 4c-e), the oscillation phenomenon disappears as the outer boundary of the eye region passes over the radar site. 


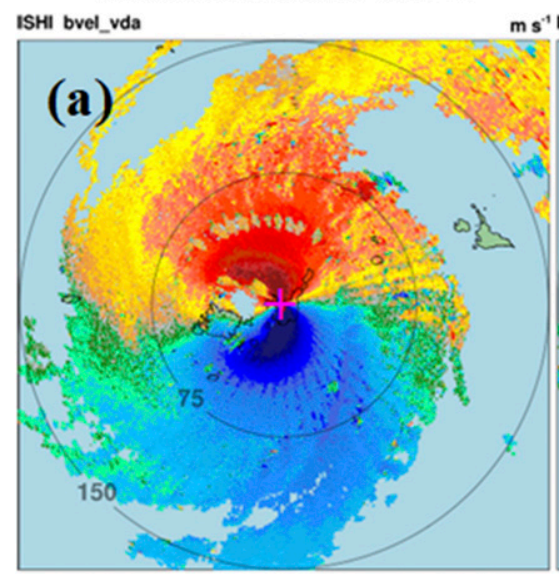
$\mathrm{m} \mathrm{s}^{-1}$ ISHI bvel_vda

\section{$0.20 \mathrm{PPI}$}

2015-0823-1225 UTC 0.20PPI

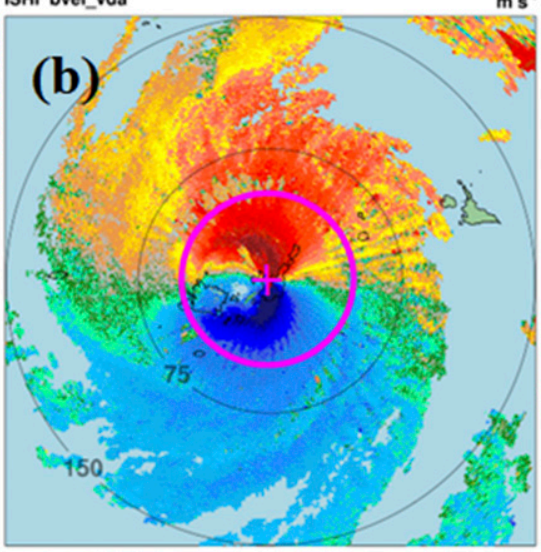
$\mathrm{m} \mathrm{s}^{-1}$ ISHI bvel_vda m s
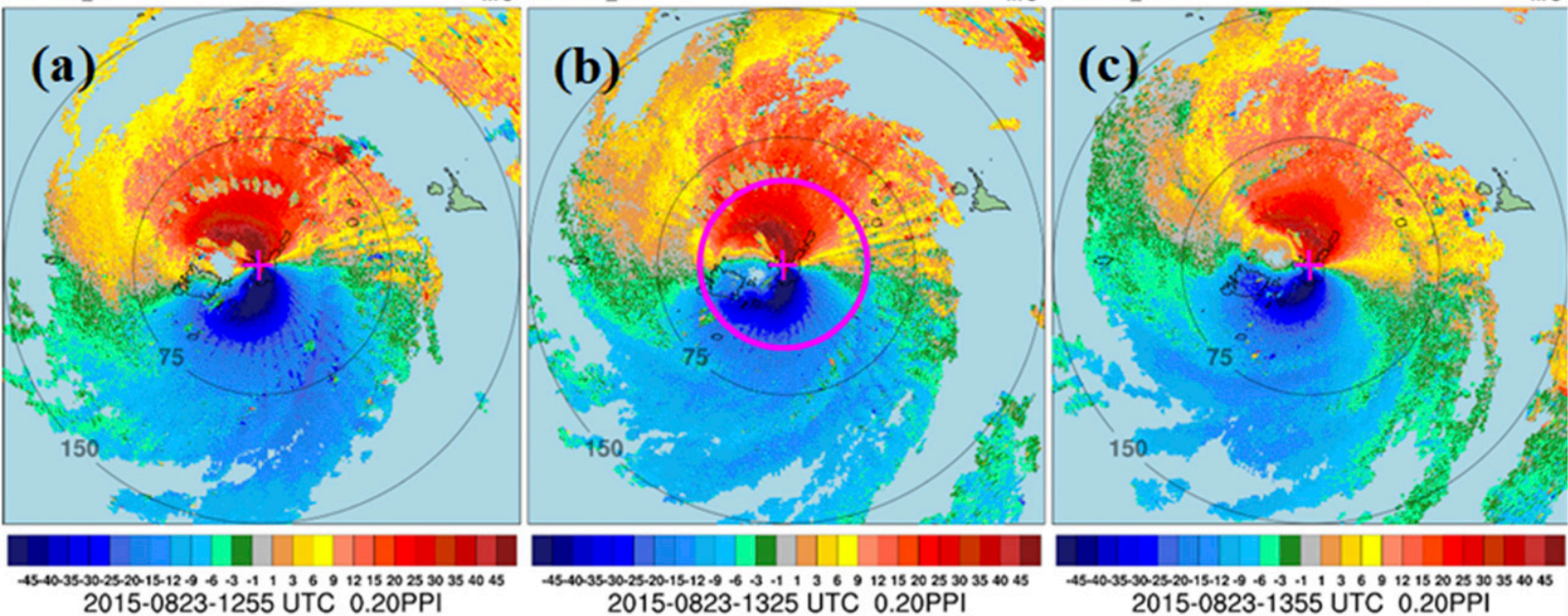

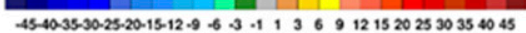
2015-0823-1325 UTC 0.20PPI

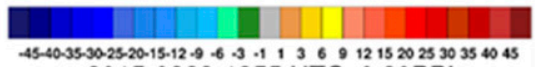
2015-0823-1355 UTC 0.20PPI

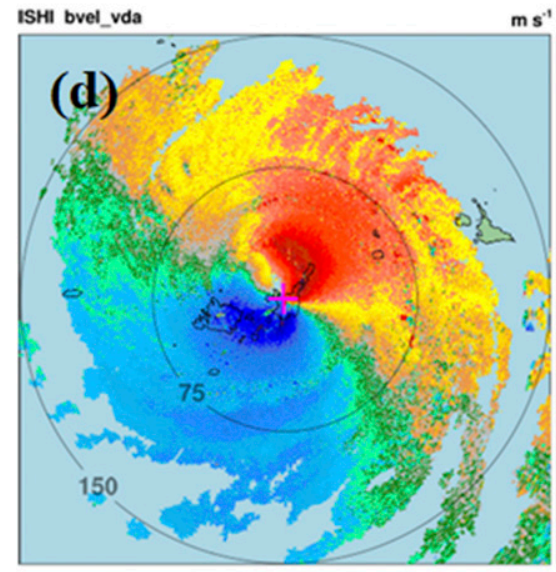

$\mathrm{m} \mathrm{s}^{-1}$ ISHI bvel_vda

$\mathrm{m} \mathrm{s}^{-1}$ ISHI bvel_vda
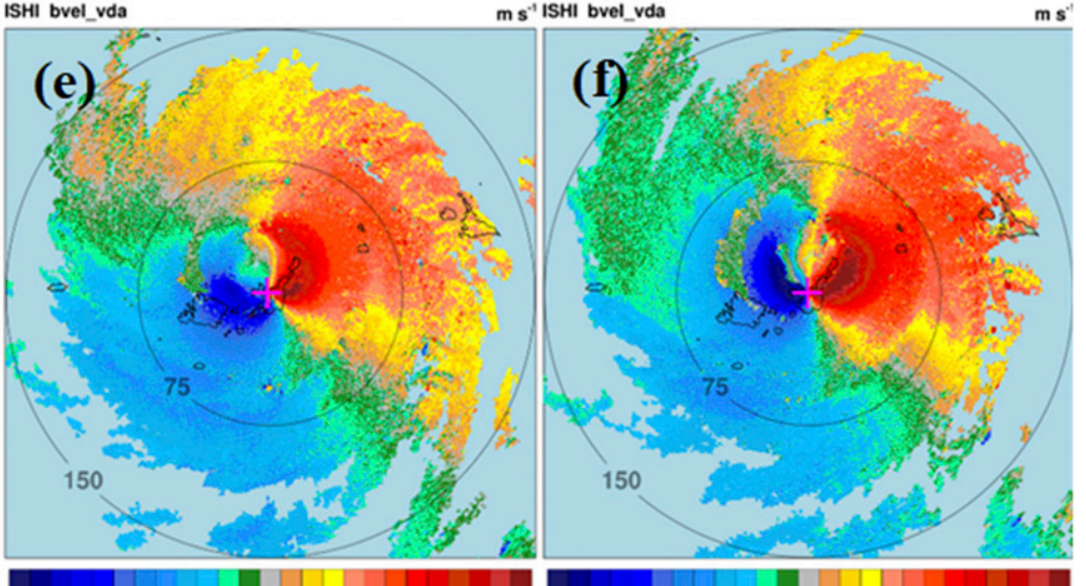

$45-40-35-30-25-20-15-12-9-6-3-11376 \quad 91215202530354045$
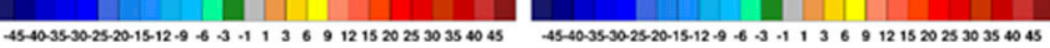

FIG. 5. As in Fig. 4, but for the Doppler velocity field, and the data in the range of $50 \mathrm{~km}$ from the radar site shown in (b) with a pink ring are used for the oscillation analyses in Figs. 10 and 11.

At 1355 UTC (Fig. 4f), the oscillation phenomenon reappears, although the strength of the signal clearly decreases. After 1425 UTC (not shown), the oscillation phenomenon disappears as Typhoon Goni continuously moves northwestward away from the radar site. In addition, the eye and eyewall are characterized by polygonal shapes that rotate over time during the analysis period, suggesting that these phenomena may be related to the vortex Rossby wave, as has been mentioned in many studies (e.g., Kuo et al. 1999; Kossin and Schubert 2001; Yang et al. 2007). The typhoon is speculated to be intensifying in accordance with the intensity analysis of Typhoon Goni documented in Shimada et al. (2018).

For the corresponding Doppler velocity field, the eyewall region is obviously characterized by an approximately symmetric dipole signature with a maximum magnitude exceeding $50 \mathrm{~m} \mathrm{~s}^{-1}$ at $1125 \mathrm{UTC}$ at an elevation angle of $0.2^{\circ}$ (Fig. 5a). Outside the eyewall region, oscillation phenomena can be observed in part of the low-reflectivity and spiral rainband regions located in the northern and eastern quadrants of the typhoon. A similar but slightly weaker oscillation signature can also be found in the spiral rainband region in the southern quadrant of the typhoon. As the outer boundary of the eye region passes over the radar site (Figs. 4c-e) from 1225 UTC to $1325 \mathrm{UTC}$, the maximum/minimum Doppler velocity observations are underestimated due to geometric distortion (Wood and Brown 1992), and the oscillation phenomenon dramatically disappears over time (Figs. $5 \mathrm{c}-\mathrm{e}$ ), similar to that in the reflectivity field (Figs. 4c-e). At 1355 UTC (Fig. 5f), the maximum/minimum inbound/outbound Doppler velocities are comparable to those from 1125 UTC to 1155 UTC because the eyewall region gradually moves away from the radar site and the abovementioned geometric distortion disappears. Compared to the oscillation phenomenon in the reflectivity field shown in Fig. 4f, the signature in the Doppler velocity is less significant. Because Doppler radars measure only the velocity of 

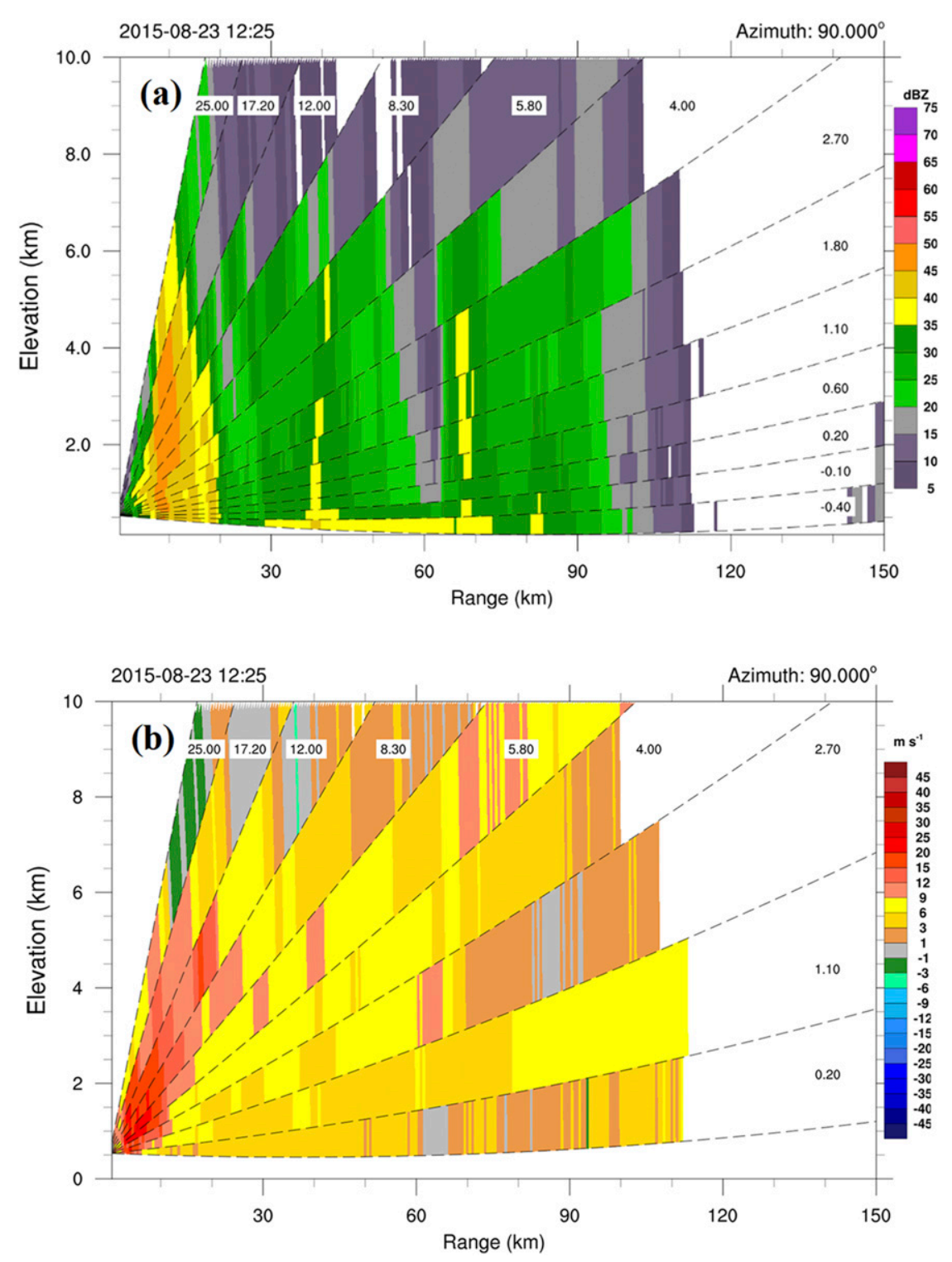

FIG. 6. (a) Reflectivity and (b) Doppler velocity $10^{\circ}$ azimuthally averaged RHI from the ISHI radar at 1225 UTC 23 Aug 2015.

precipitation particles along the viewing direction, the amplitudes of the oscillation signals in the Doppler velocity field are not comparable among different azimuths even though the winds are horizontally homogenous; the vertical gradient of the Doppler velocity field enhances the variation in the oscillation signals, as shown in the reflectivity field.

To further investigate the contributions of the vertical distributions to reflectivity and Doppler velocity oscillation phenomena, the $10^{\circ}$ azimuthally averaged radar range height indicator (RHI) from volume scan data are analyzed. The analysis data at 1225 UTC are chosen to avoid data contamination by antenna oscillations, as shown in Fig. 4c. Figure 6a shows an example of the reflectivity RHI to the east of the radar site. The reflectivity generally decreases with height. The eyewall area with reflectivity greater than $35 \mathrm{dBZ}$ located at ranges of approximately 5-20 km shows a well-organized structure vertically. Outside the eyewall, sharp vertical gradients near the sea surface are found at ranges of approximately $30-70 \mathrm{~km}$ that primarily result from enhanced sea clutter signals, as mentioned above. For the corresponding Doppler velocity field (Fig. 6b), the vertical distributions are relatively noisy compared to those in the reflectivity field. The Doppler velocities are generally small, with values from -1 to $20 \mathrm{~m} \mathrm{~s}^{-1}$, because the wind directions and radar viewing angles are approximately perpendicular. The Doppler velocities are near zero in the range of $60-100 \mathrm{~km}$ at $0.2^{\circ}$, which is possibly due to sea clutter signals 

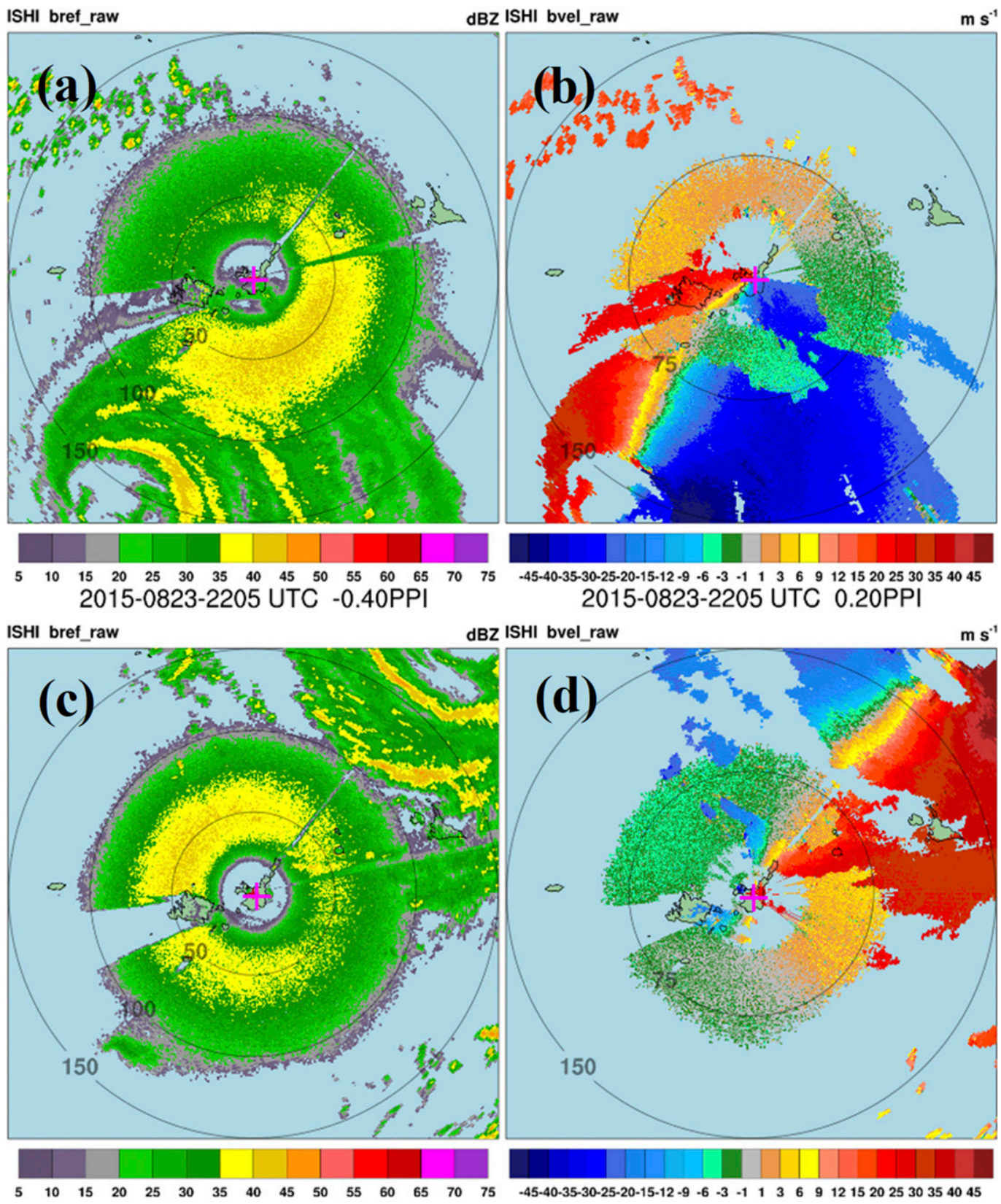

FIG. 7. (a) Reflectivity field at $-0.4^{\circ}$ and (b) Doppler velocity field at $0.2^{\circ}$ from the ISHI radar at 0000 UTC 23 Aug 2015. (c),(d) As in (a) and (b), but at 2200 UTC 23 Aug 2015.

enhancing the vertical gradients of the Doppler velocity. Because the Doppler velocity is a function of wind speed, wind direction, and radar viewing direction, the vertical gradients in the Doppler velocity field show more variations than those in the reflectivity field, as previously mentioned.

As mentioned above, the oscillation signals in the reflectivity and Doppler velocity fields are most significant at the lowest elevations, which may possibly be enhanced by sea clutter signals. Sea clutter phenomena are frequently detected for radars located close to the coastline (e.g., Collier 1998; Ryzhkov et al. 2002) and can be observed even for radars installed atop mountains (e.g., Chang et al. 2009, 2019). The ISHI radar is situated on a mountain top on Ishigaki Island less than $10 \mathrm{~km}$ from the coastline; thus, sea clutter signals are frequently contained within the radar observations due to the return of sea surface signals from the sidelobe of the radar beam, especially under strong wind 


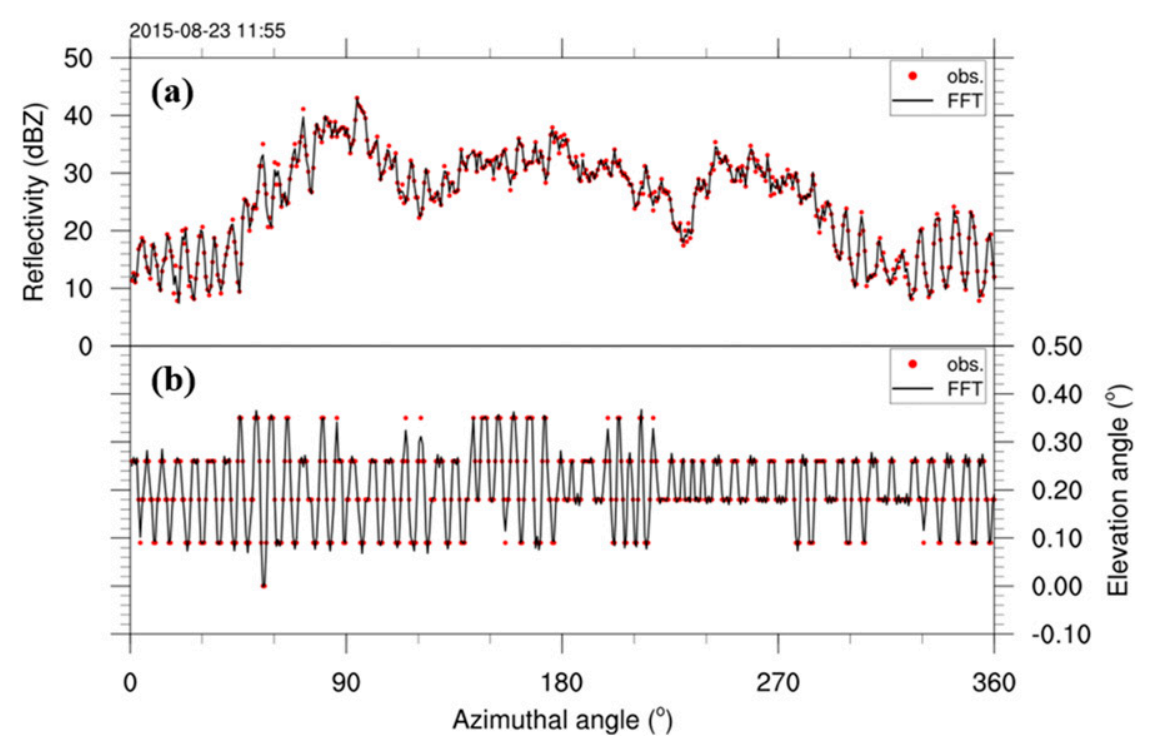

FIG. 8. Azimuthal distributions of the (a) reflectivity and (b) elevation angle at an elevation angle of $0.2^{\circ}$ in the range of $50 \mathrm{~km}$ from the radar site (as shown in Fig. $3 \mathrm{~b}$ ) at 1155 UTC 23 Aug 2015. The red dots indicate the observed reflectivities and elevation angles, and the associated black curves are generated based on the wavenumbers calculated from the FFT analysis.

conditions (e.g., Collier 1998). Figure 7 shows examples of sea clutter signals that occurred as Typhoon Goni approached and moved away from the radar site. Significant sea clutter signals cover the radar site and show a "donut" pattern because the radar sidelobe gradually descends from the mountain top and then ascends (Miller et al. 1998), resulting in blank areas within $\sim 30 \mathrm{~km}$ and beyond $\sim 90 \mathrm{~km}$ of the radar site. Additionally, several blockages are caused by the terrain to the southwest and northeast of the radar site; such blockages can also be ascertained when echoes from the outer rainband of Typhoon Goni are embedded with sea clutter signals. A similar sea clutter pattern is found in the Doppler velocity field, which shows that the values are confined within a range from -6 to $6 \mathrm{~m} \mathrm{~s}^{-1}$, which are significantly smaller than the ambient signals caused by typhoon circulations.

These sea clutter signals weaken when Typhoon Goni's eyewall approaches the radar site because the weather signals are stronger than those from the sea clutter, thus dominating the observations, as shown in the eyewall areas illustrated in Fig. 3 and Fig. 4. The pronounced oscillation phenomena in both the reflectivity and Doppler velocity fields may have been enhanced by large differences between Typhoon Goni's precipitation signals and the sea clutter signals.

\section{b. Oscillation analyses}

Antenna oscillations substantially affect radar observations, as shown in Figs. 3-5. Figure 8a shows the azimuthal distribution of reflectivity at an elevation angle of $0.2^{\circ}$ and a range of $50 \mathrm{~km}$ at 1155 UTC 23 August 2015. The reflectivity intensities range from 8 to $44 \mathrm{~dB} Z$ for all azimuths and present high-frequency oscillations with a maximum amplitude of $16 \mathrm{~dB}$ at azimuths of approximately $330^{\circ}-360^{\circ}$. Figure $8 \mathrm{a}$ also shows that the curve derived from the FFT analysis with wavenumbers ranging from 0 to 200 fits the reflectivity data well. Similar to the reflectivity oscillation results, the hardware-recorded elevation angle as a function of azimuth shows significant high-frequency oscillations, with a maximum amplitude of $\sim 0.2^{\circ}$ at an azimuth of approximately $60^{\circ}$ (Fig. 8b). The curve composed of the wavenumbers from the FFT analysis also well fit the hardware-recorded elevation angle data.

Because the antenna and reflectivity oscillations are significant and primarily contributed by wavenumbers from 40 to 70 shown in Fig. 8a, wavenumbers in these ranges are extracted to highlight the phase relationship between the antenna and reflectivity oscillation signals although the other wavenumbers could partially contribute to the oscillation signals. A phase shift signature (Fig. 9) and a negative correlation (correlation coefficient of -0.5 ) are found between the antenna and reflectivity oscillation signals decomposed from wavenumbers 40 to 70 . This finding indicates that oscillating reflectivity values will decrease (increase) as the antenna elevation angle increases (decreases) during an antenna oscillation period. The reflectivity field exhibits an oscillation approximately $180^{\circ}$ out of phase with the antenna oscillation because the radar beams point toward the ocean and detect sea clutter or the strong reflectivity gradient when the amplitude of the elevation angle is negative, and vice versa. The results are consistent with the reflectivity RHI analysis (Fig. 6a) that the reflectivity generally decreases with increasing height.

For the Doppler velocity field at $0.2^{\circ}$ in the range of $50 \mathrm{~km}$ (Fig. 10), oscillation signals are still present, but the amplitudes 


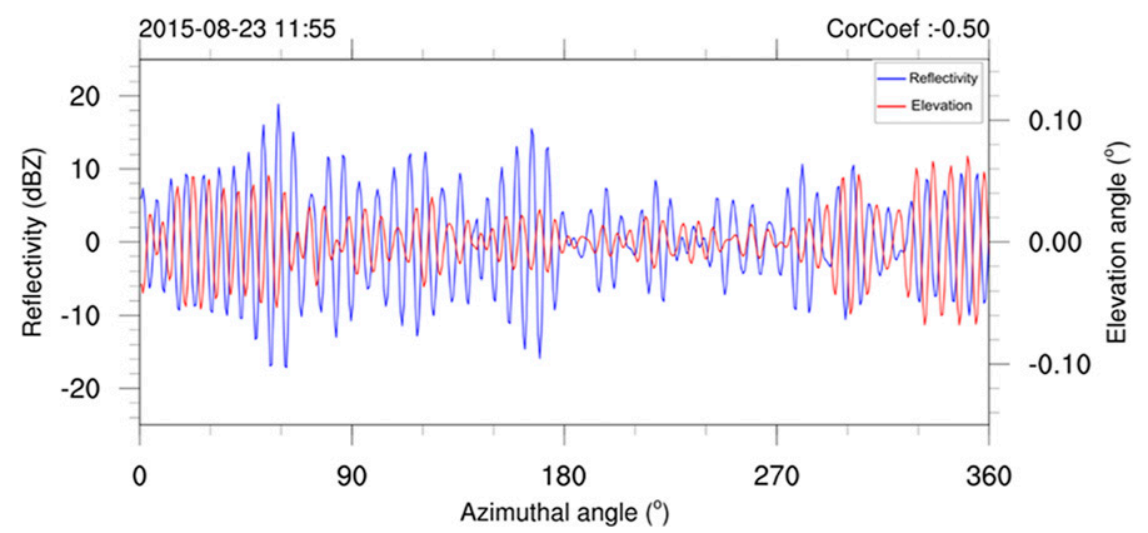

FIG. 9. As in Fig. 8, but for the azimuthal distributions of the reflectivity (blue curve) and elevation angle amplitudes (red curve) at an elevation angle of $0.2^{\circ}$ generated based on wavenumbers from 40 to 70 .

are not comparable to those in the reflectivity field. As mentioned above, the amplitudes of the oscillation signals in the Doppler velocity field are not comparable among different azimuths, and the strong vertical gradient of Doppler velocities in the eyewall region enhances the variation in oscillation signals, as observed at azimuths of $0^{\circ}-45^{\circ}$, whereas sea clutter contributes to the significant signals detected at azimuths of $300^{\circ}-360^{\circ}$.

From the analyses of the elevation angle amplitudes for different wavenumbers and 13 preset elevation angles from $-0.4^{\circ}$ to $25.0^{\circ}$ (Fig. $11 \mathrm{a}$ ), amplitudes greater than $0.02^{\circ}$ occur at wavenumbers of approximately 45 to 70 for all elevation angles. Based on the given antenna rotational speed of $4 \mathrm{rpm}$ for the ISHI radar, the corresponding frequencies (periods) range from $2.67 \mathrm{~s}^{-1}(0.38 \mathrm{~s})$ to $4.67 \mathrm{~s}^{-1}$ $(0.21 \mathrm{~s})$. In addition, antenna oscillations influence the data at all elevation angles, with a maximum elevation angle amplitude greater than $0.08^{\circ}$ at wavenumber 56 at an elevation angle of $1.1^{\circ}$. Reflectivity amplitudes for different wavenumbers and 13 preset elevation angles from $-0.4^{\circ}$ to $25.0^{\circ}$ are shown in Fig. 11b. FFT analyses are not performed for elevation angles of $17.2^{\circ}$ and $25.0^{\circ}$ because the available quantity of data are less than half (256) of the full radar range at $50 \mathrm{~km}$. The reflectivity FFT analysis demonstrates that relatively large amplitudes are confined to elevation angles $<0.6^{\circ}$ and that the maximum reflectivity amplitude larger than $1 \mathrm{~dB}$ occurs at $-0.1^{\circ}$ for wavenumbers between approximately 45 and 60 . Notably, the maximum amplitude with a value greater than $2 \mathrm{~dB}$ is found at the elevation angle of $-0.1^{\circ}$ rather than at the lowest elevation angle of $-0.4^{\circ}$, indicating that the oscillation signals at $-0.4^{\circ}$ are seriously contaminated by sea clutter signals, as shown in Fig. 7, because of the decreasing vertical reflectivity gradient at this elevation angle. The oscillation signals at higher elevations are much weaker than those at lower elevations, as documented in section $3 \mathrm{a}$.

Regarding the Doppler velocity amplitudes for different wavenumbers over 9 preset elevation angles from $0.2^{\circ}$ to $25.0^{\circ}$ (Fig. 11c), relatively weak signals are discovered compared with those in the reflectivity field. The most significant signals occur at the lowest elevation angle of $0.2^{\circ}$, with a maximum value greater than $1.5 \mathrm{~m} \mathrm{~s}^{-1}$ approximately between wavenumbers 48 and 55 . Furthermore, the amplitudes of oscillation signal larger than $0.5 \mathrm{~m} \mathrm{~s}^{-1}$ are found over a wide wavenumber range, indicating that more noise is

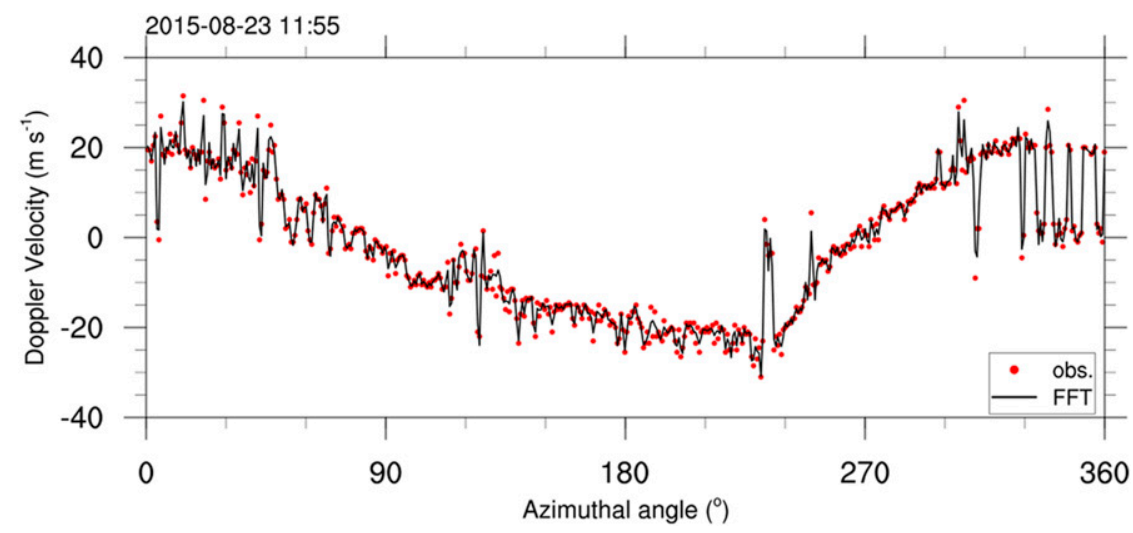

FIG. 10. As in Fig. 8, but for the azimuthal distribution of Doppler velocities at an elevation angle of $0.2^{\circ}$. 

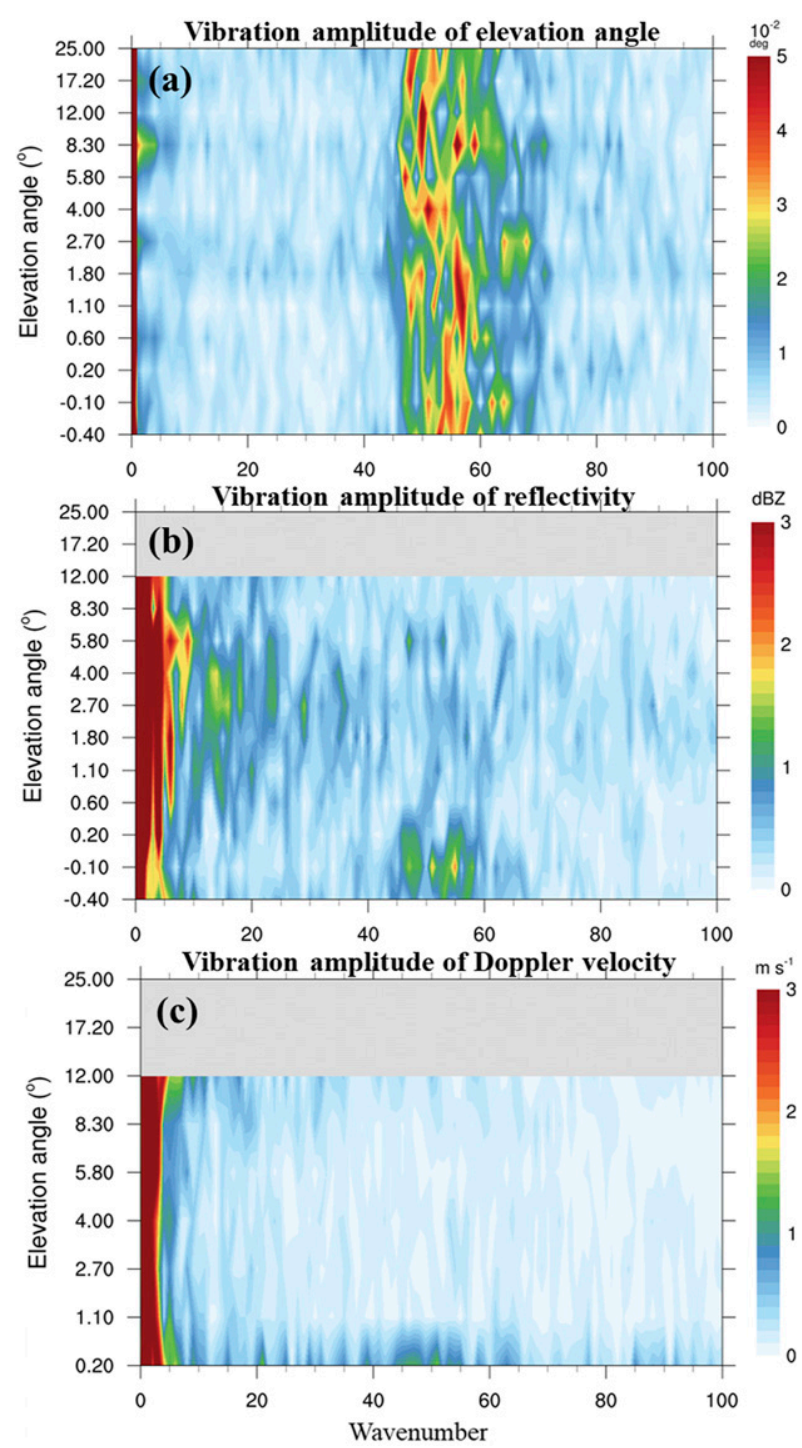

FIG. 11. (a) Elevation angle, (b) reflectivity, and (c) Doppler velocity amplitudes as a function of wavenumber for 13 preset elevation angles from $-0.4^{\circ}$ to $25.0^{\circ}$ at 1155 UTC 23 Aug 2015. The elevation angle and reflectivity volume data are combined from surveillance and Doppler modes. The Doppler velocity volume data are only from the Doppler mode.

triggered in the Doppler velocity fields. This finding indicates that oscillation signals are enhanced by the vertical gradient of the Doppler velocity and the contamination by sea clutter signals under the unequal amplitude responses at certain azimuths to antenna oscillations, as mentioned in section $3 \mathrm{a}$.

\section{c. Velocity-azimuth display analysis}

Because there are no wind observations at the ISHI radar site, which is located near the top of Mt. Omoto-dake (525.5 $\mathrm{m}$ above mean sea level), velocity-azimuth display (VAD) analyses (Lhermitte and Atlas 1961; Browning and

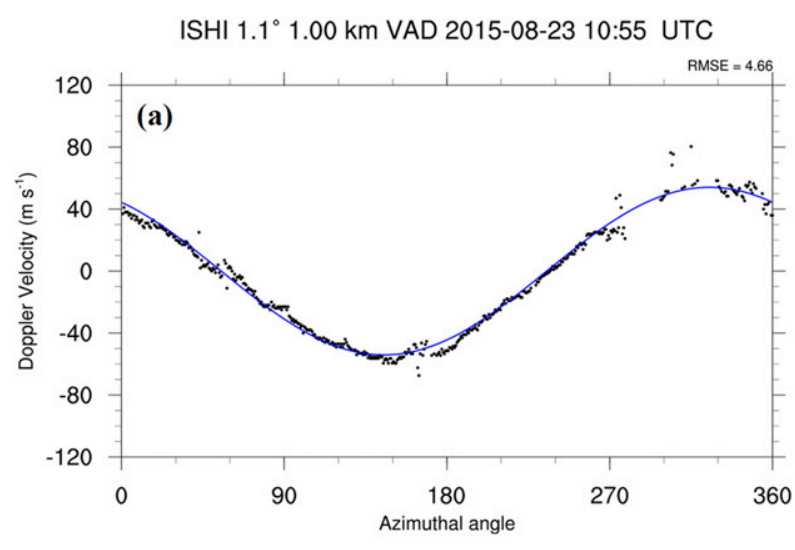

ISHI $1.1^{\circ} 1.00 \mathrm{~km}$ VAD 2015-08-23 12:55 UTC

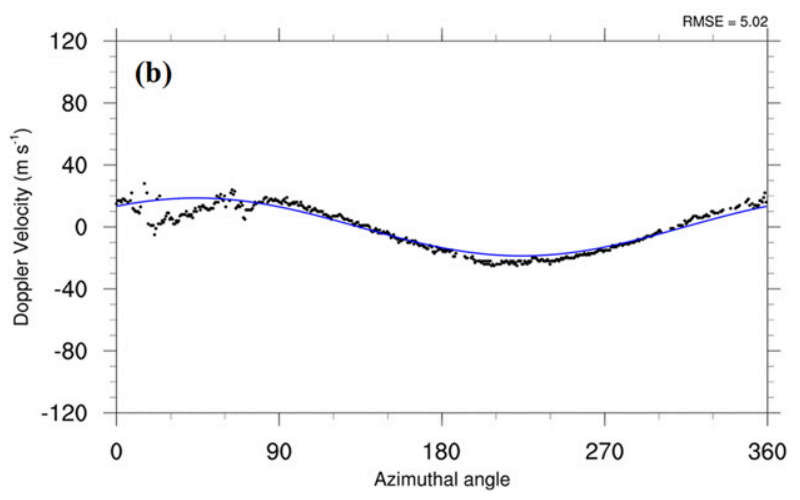

FIG. 12. VAD analyses from (a) 1055 and (b) 1355 UTC 23 Aug 2015. The blue lines indicate the fitted curves for the VAD analyses. The root-mean-square errors (RMSEs) are also indicated.

Wexler 1968) are conducted to estimate the wind speeds during Typhoon Goni's passage. However, the assumption of linearity utilized in the VAD algorithm tends to break down when intense cyclonic storms, such as tropical cyclones, are considered (Donaldson and Harris 1989). Donaldson (1991) further documented that higher-order Fourier coefficients are generally underestimated by the VAD technique in a cyclonic wind field with varying curvature and diffluence, and the errors can be represented by the ratio $r / R$, namely, the ratio of the VAD scanning radius $r$ to the distance from the radar to the cyclone center $R$. Donaldson (1991) also found that the potential-vortex fit (PVF) (the ratio of the shearing deformation term to twice the estimated curvature term) is underestimated by $20 \%$ for $r / R=1$ but only by $3.4 \%$ for $r / R=0.5$ in an idealized Rankine vortex (Donaldson 1991). Therefore, the underestimation from this source will be substantially less than $3.4 \%$ if $r$ is chosen to be $1 \mathrm{~km}$ for an estimated $R$ of $30 \mathrm{~km}$ for Typhoon Goni. Consequently, VAD analyses confined at a radial distance of $1 \mathrm{~km}$ can reasonably estimate the winds around the ISHI radar site during Typhoon Goni's passage.

Furthermore, to avoid the influences of Doppler velocity fluctuations due to ground clutter and antenna oscillations at the 

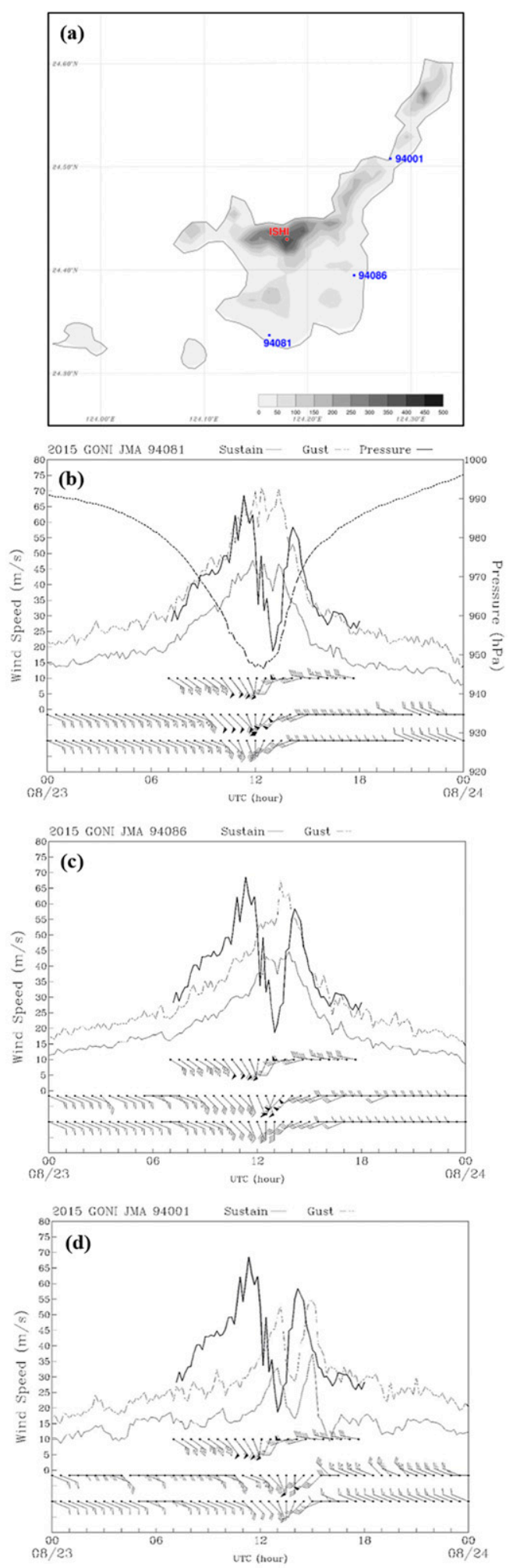

FIG. 13. (a) Locations of the three weather stations (blue dots) and radar site (red dot) on Ishigaki Island. The gray shading represents the terrain height. The temporal distributions of the 10-min sustained wind speeds (solid lines), gust wind speeds (dashed lines), and pressure (dotted line) observed at stations lowest elevation angle of $0.2^{\circ}$ (Fig. 4b), Doppler velocity data for an elevation angle of $1.1^{\circ}$ at a radial distance of $1 \mathrm{~km}$ are chosen for the VAD analysis. The temporal period for VAD winds is less than $18 \mathrm{~s}$, as shown in Fig. 1. Figure 12 shows examples of the VAD analyses at 1055 and 1255 UTC. The maximum inbound and outbound Doppler velocities are approximately $70 \mathrm{~m} \mathrm{~s}^{-1}$ at 1055 UTC (Fig. 12a), when Typhoon Goni's eyewall approached the radar site. As shown in Fig. 12a, the Doppler velocities are generally represented by the fitted curve of the VAD analyses. The inbound and outbound Doppler velocities present a considerably scattered distribution with maximum values of approximately $80 \mathrm{~m} \mathrm{~s}^{-1}$ as Typhoon Goni's eyewall covered the radar site. As Typhoon Goni's eye region moved toward the radar site at 1255 UTC (Fig. 12b), the maximum inbound and outbound velocities dramatically decreased to approximately $40 \mathrm{~m} \mathrm{~s}^{-1}$. In the following subsection, the VAD-retrieved winds will be compared with the surface winds observed at three weather stations on Ishigaki Island to analyze the characteristics of the wind differences among them.

\section{d. Wind analyses related to the antenna oscillations}

Three stations located on Ishigaki Island (Fig. 13a) are selected to investigate the spatial-temporal variations in surface winds. Figure $8 \mathrm{~b}$ shows the temporal distributions of 10-min sustained winds, gust winds, and pressure between 0000 UTC 23 August and 0000 UTC 24 August observed at Ishigaki station 94081 in the southwestern region of Ishigaki Island. The sustained and gust wind speeds gradually increase while the pressure gradually decreases. The maximum sustained and gust wind speeds are 47 and $70 \mathrm{~m} \mathrm{~s}^{-1}$ at 1200 and 1320 UTC, respectively, while the minimum pressure of $945 \mathrm{hPa}$ occurs at approximately 1300 UTC.

To analyze the spatial-temporal variations in the wind differences with altitude, the surface winds, and VADretrieved winds are compared. In comparison with the VAD analysis results, the surface gust wind speeds are close to the VAD-retrieved wind speeds before 1200 UTC and after 1400 UTC (Fig. 13b). Although station 94081 is approximately $9.5 \mathrm{~km}$ southwest of the radar site, a dramatic difference between the VAD-retrieved and surface gust winds is found between 1200 and 1400 UTC, with a maximum value of $50 \mathrm{~m} \mathrm{~s}^{-1}$. The radar site may have already been within the eye region during this period, whereas the surface station would still have been affected by Typhoon Goni's eyewall, which is why high wind speeds remain at the surface. The large differences between the surface and VAD-retrieved winds are not surprising because the wind speeds in the planetary boundary layer (PBL) generally decrease more rapidly with decreasing

(b) 94081 , (c) 94086, and (d) 94001 on Ishigaki Island. The bold solid lines indicate the wind speeds derived from radar VAD analysis. The winds from the VAD analyses illustrated in section $3 c$ are also indicated by wind barbs with triangles, full barbs, and half barbs for 50,10 , and $5 \mathrm{~m} \mathrm{~s}^{-1}$ every $30 \mathrm{~min}$, respectively; gust and sustained winds are shown from top to bottom at the bottom of the figures. 

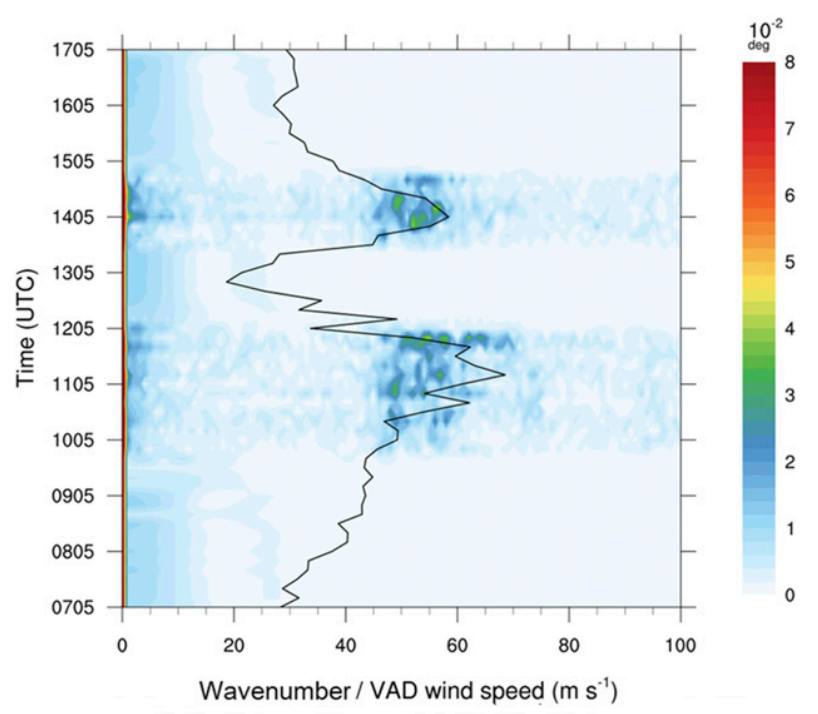

FIG. 14. Temporal composite of the elevation angle amplitudes at a preset elevation angle of $-0.1^{\circ}$ as a function of wavenumber derived from the FFT analysis between 0705 and 1705 UTC 23 Aug 2015. The solid line indicates the VAD wind speeds shown in Fig. 12.

height due to frictional effects (Monin and Obukhov 1954). In addition, determining surface winds from radar observations involves uncertainties, such as uncertainties in the estimations of the roughness length and gust factors, even though the Doppler-retrieved winds are nearly accurate (Hayes 2011). However, the differences in the temporal evolution are significant during Goni's passage, indicating that the horizontal and vertical wind structures and movement of the typhoon strongly contribute to the wind speed differences.

In the southeastern region of Ishigaki Island, the sustained and gust wind speeds at station 94086 (approximately $7.3 \mathrm{~km}$ southeast of the radar site) show similar distributions to those at station 94081 on Ishigaki Island. The maximum sustained and gust wind speeds are approximately 43 and $67 \mathrm{~m} \mathrm{~s}^{-1}$, respectively, occurring at 1220 and 1350 UTC (Fig. 13c). The times of the peak wind speeds from the VAD analysis present an approximate lag of $1-2 \mathrm{~h}$ relative to the times of the peak surface wind speeds observed at station 94086 as the eyewall approaches. Because station 94086 is situated in the plain area in the southern region of the island, the wind speed distributions at this station are similar to those at station 94081, with a maximum gust wind speed of $\sim 66 \mathrm{~m} \mathrm{~s}^{-1}$. Differences of approximately $5-20 \mathrm{~m} \mathrm{~s}^{-1}$ are observed because the eyewall affects the radar site even when the station is still outside the eyewall region. Therefore, a 1-2-h lag is observed in the peak gust wind speed occurrence. At station 94001 (Fig. 13d), which is located in the northeastern region of Ishigaki Island (approximately $12.8 \mathrm{~km}$ northeast of the radar site), peak wind speeds are not observed, and the wind speeds are lower than those at stations 94081 and 94086 . This phenomenon is possibly related to the station being situated on the lee side of Mt. Omoto-dake because the wind speeds could have been

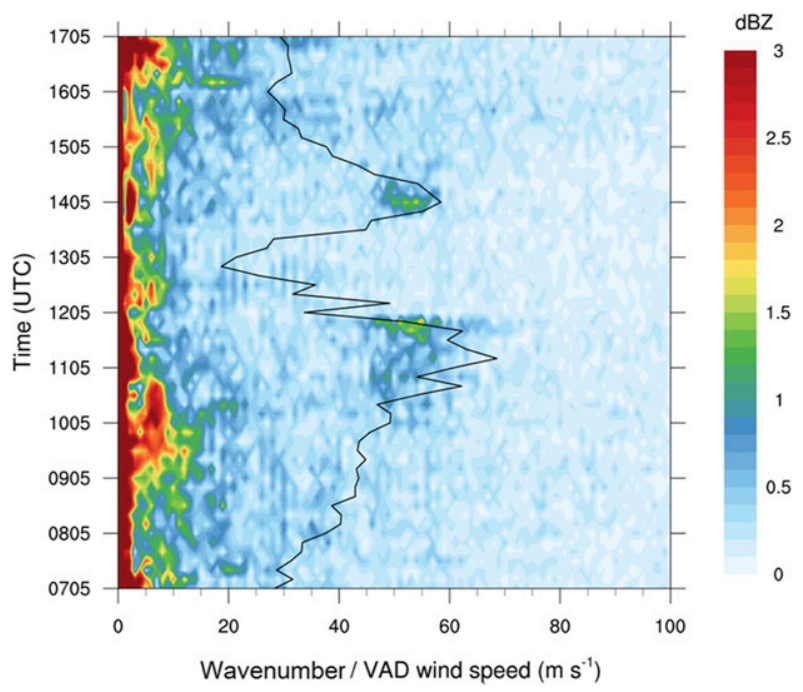

FIG. 15. As in Fig. 14, but for the reflectivity amplitudes.

slowed down by the blocking effect (e.g., Chang et al. 1993; Lin et al. 2006).

After the eyewall gradually moves away from Ishigaki Island, the differences between the wind speeds from the surface observations and VAD analysis significantly decrease. Generally, the location and altitude differences potentially result in wind speed differences between the radar site and weather stations. The circulation and movement of the typhoon also contribute to these wind speed differences.

Figure 14 shows a Hovmöller diagram of the elevation angle amplitudes for wavenumbers 0 to 100 between 0705 and 1705 UTC 23 August 2015 at a preset elevation angle of $-0.1^{\circ}$. The wind speeds derived from the VAD analysis in the same analyzed period are overlaid. Elevation angle oscillation amplitudes exceeding $0.02^{\circ}$ between wavenumbers 45 and 70 are found between 0955 and 1205 UTC and between 1335 and 1445 UTC. The most pronounced elevation angle oscillation amplitudes greater than $0.03^{\circ}$ in the first oscillation period occur at 1155 UTC for wavenumbers between 45 and 70 . In the second oscillation period, the most pronounced amplitudes greater than $0.03^{\circ}$ occur at 1405 UTC for wavenumbers between 45 and 60 . These high amplitudes in the wavenumber 40-70 band are not found between these two oscillation periods.

Based on a comparison with the VAD-retrieved winds, the amplitudes in the wavenumber 40-70 band increase when the wind speeds are greater than $45 \mathrm{~m} \mathrm{~s}^{-1}$ and significantly decrease when the wind speeds are equal to and lower than $45 \mathrm{~m} \mathrm{~s}^{-1}$, especially for the period of quiescence between the two periods of pronounced amplitudes. These results imply that wind-induced radar tower vibrations cause antenna oscillations and influence the quality of both reflectivity and Doppler velocity fields.

The Hovmöller diagram of reflectivity amplitudes for $-0.1^{\circ}$ at 1155 UTC is shown in Fig. 15. Regardless of the low wavenumber components generated by the predominant reflectivity structures of the eyewall and rainband regions, the most 
2005-0717-1736 UTC 0.50PPI

RCHL bref_raw

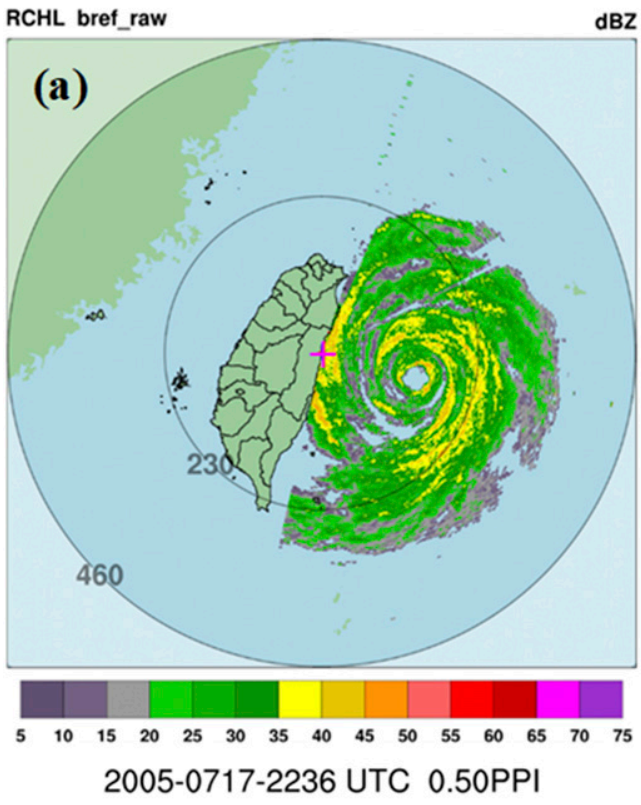

$d B Z$

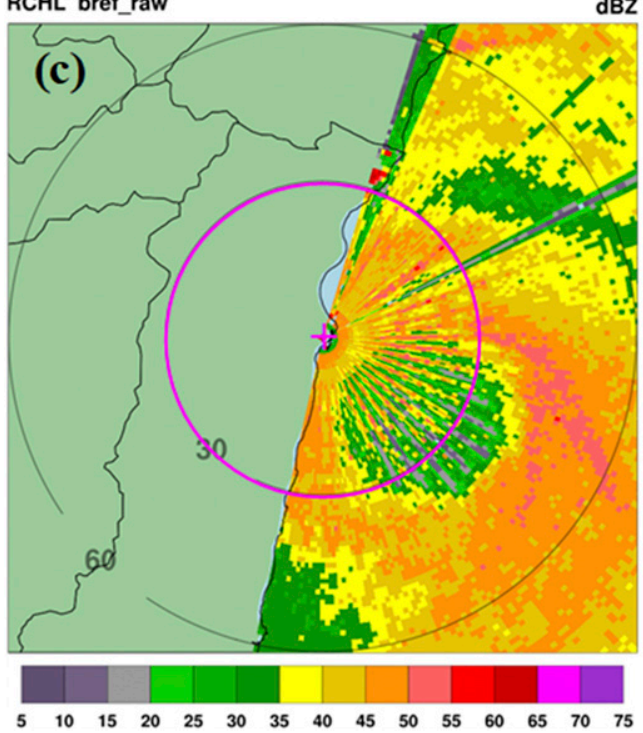

2005-0717-2236 UTC 0.50PPI

RCHL REF

dBZ

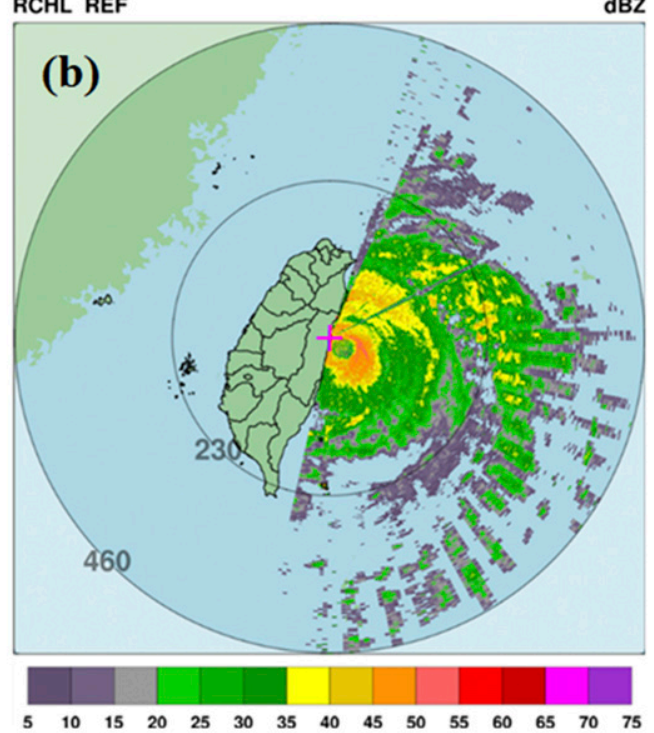

2005-0717-2233 UTC 0.50PPI
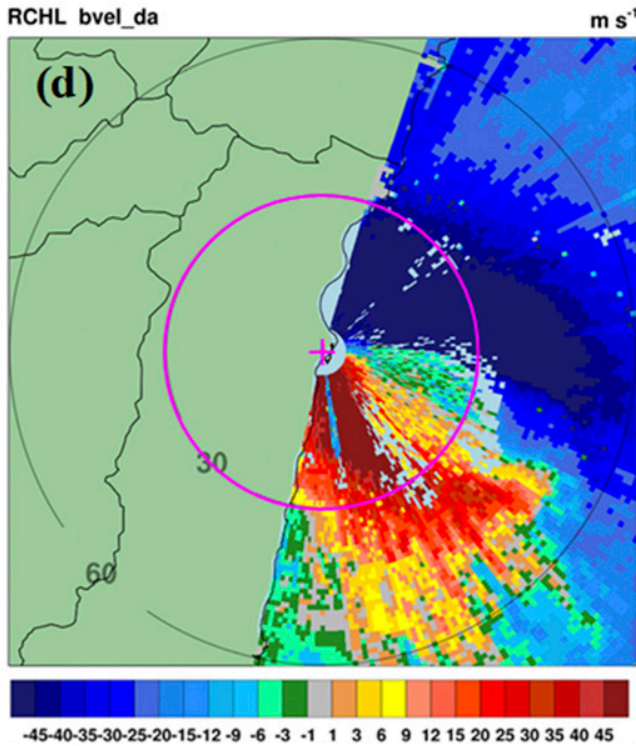

FIG. 16. RCHL radar reflectivities for Typhoon Haitang at (a) 1736 and (b) 2236 UTC 17 Jul 2005. (c) As in (b), but for the area near the inner core region and (d) Doppler velocity field at 2233 UTC. The data in the range of $30 \mathrm{~km}$ from the radar site shown in (c) and (d) with a pink ring are used for the oscillation analyses in Fig. 17.

pronounced amplitudes of the reflectivity oscillation signals, with wavenumbers between 45 and 60 , are consistent with those of the elevation angle oscillation signals (Fig. 15) and the oscillation phenomena described in section $3 \mathrm{a}$.

\section{e. Antenna oscillation during Typhoon Haitang}

Extremely strong winds resulting from severe storms, such as tropical cyclones, are frequently observed by radars worldwide. However, tropical cyclone wind maxima do not frequently pass over radar sites. Nevertheless, a radar tower could oscillate, causing antenna oscillations and subsequently influencing the data quality of radar observations, when strong tropical cyclones, such as Typhoon Goni, sweep past the radar site.

Typhoon Haitang (2005) made landfall in Taiwan and followed a north-northwestward track before exhibiting a sharp southward turn and a slow cyclonic loop off the eastern coast of Taiwan between 2300 UTC 17 July and 0700 UTC 18 July (Jian and Wu 2008). A similar oscillation phenomenon observed at RCHL is found for Typhoon Haitang when the eyewall affected eastern Taiwan. The RCHL Doppler radar (Fig. 1), which is located in Hualien, 


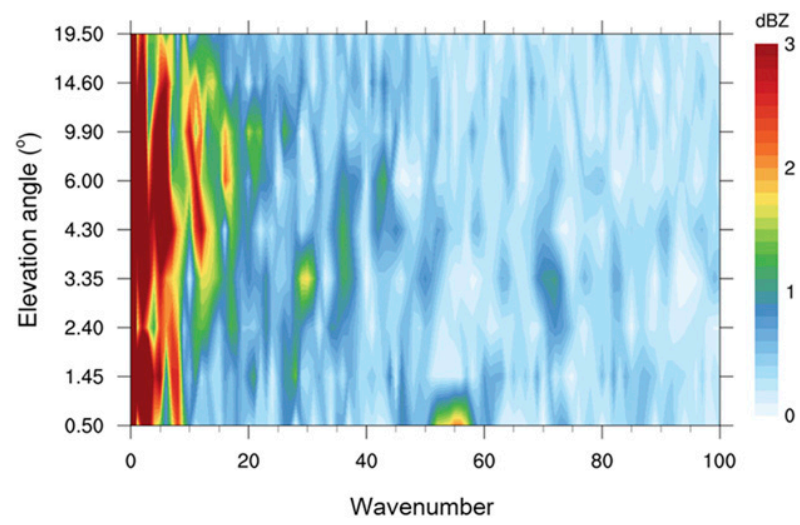

FIG. 17. RCHL reflectivity amplitude as a function of wavenumber and elevation angle from $0.5^{\circ}$ to $19.0^{\circ}$ at 2236 UTC 17 Jul 2005.

captured the well-organized structures of the eye, eyewall, and spiral rainband during Typhoon Haitang's passage over eastern Taiwan (Fig. 16). No reflectivity field was observed west of the RCHL radar site because electromagnetic waves were not transmitted at low to middle elevations (Chang et al. 2009). In addition, no elevation angles were recorded for individual beams for RCHL, so only the reflectivity and Doppler velocity fields are available for the oscillation analyses.

Typhoon Haitang exhibited a symmetric circular eyewall structure with a radius of $\sim 30 \mathrm{~km}$ within approximately $150 \mathrm{~km}$ to the east-southeast of the radar site at 1736 UTC (Fig. 16a). Intensification occurred when Typhoon Haitang moved close to the radar site. Despite the outward tilting of the vertical eyewall (e.g., Jorgensen 1984; Marks and Houze 1987; Hazelton and Hart 2013), the eyewall radius slightly decreased to $25 \mathrm{~km}$ and its intensity was dramatically enhanced (Fig. 16b) as the eyewall swept over the radar site. In addition, oscillation signals with a regular radial pattern were found in the outer spiral rainband region in the range from 230 to $460 \mathrm{~km}$. The reflectivities generally enhance/disappear when the elevation decreases/increases during the antenna oscillation period, with a higher radar beam height near the storm top. The disappearance of reflectivity is caused by weak signal return from hydrometeors that is below the minimum detectable signal (MDS) for the radar system. This condition is similar to the negative vertical gradient of reflectivity that would also enhance oscillation signatures. Oscillation signals were also obvious within the eye region, which were possibly enhanced by a strong vertical gradient of reflectivity resulting from sea clutter signals, as depicted in Fig. 16c. For safety reasons, the radar was shut down due to strong wind speeds; thus, data were not collected after 2236 UTC 17 July. The Doppler velocity field shows a typical symmetric dipole signature with a maximum magnitude exceeding $60 \mathrm{~m} \mathrm{~s}^{-1}$ at $2233 \mathrm{UTC}$ at an elevation angle of $0.5^{\circ}$ (Fig. 16d). Similar to Typhoon Goni (Fig. 5), oscillation signals are also found in the Doppler velocity field around the eye and eyewall regions (Fig. 16d), potentially increasing the uncertainties in the retrieval estimates of the typhoon

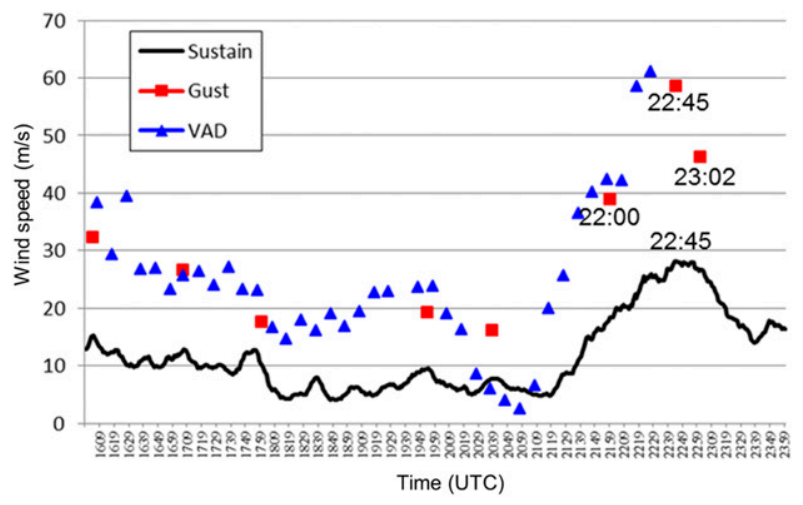

FIG. 18. Temporal distributions of the 10-min sustained winds (1-min update frequency) (heavy line) and hourly gust winds (red squares) observed at the Hualien weather station and the VAD wind speeds (blue triangles) retrieved from the RCHL radar data between 1600 UTC 7 Jul and 0000 UTC 18 Jul.

center, intensity, and structures (e.g., Wood and Brown 1992; Lee et al. 1999; Lee and Marks 2000).

Similar to the FFT analysis in Fig. 11b, Typhoon Haitang's reflectivity amplitudes at a radius of $30 \mathrm{~km}$ for different wavenumbers and elevation angles ranging from $0.5^{\circ}$ to $19.5^{\circ}$ are shown in Fig. 17. The larger reflectivity amplitudes are confined between wavenumbers 50 and 60 at a $0.5^{\circ}$ elevation angle, with a maximum reflectivity amplitude larger than $1 \mathrm{~dB} Z$. Based on the antenna rotational speed of $2 \mathrm{rpm}$ for the RCHL radar, the corresponding frequencies (periods) range from approximately $1.7 \mathrm{~s}^{-1}(0.59 \mathrm{~s})$ to $1.93 \mathrm{~s}^{-1}(0.52 \mathrm{~s})$. Figure 18 shows the temporal distributions of the 10 -min sustained (1-min update frequency) and hourly gust wind

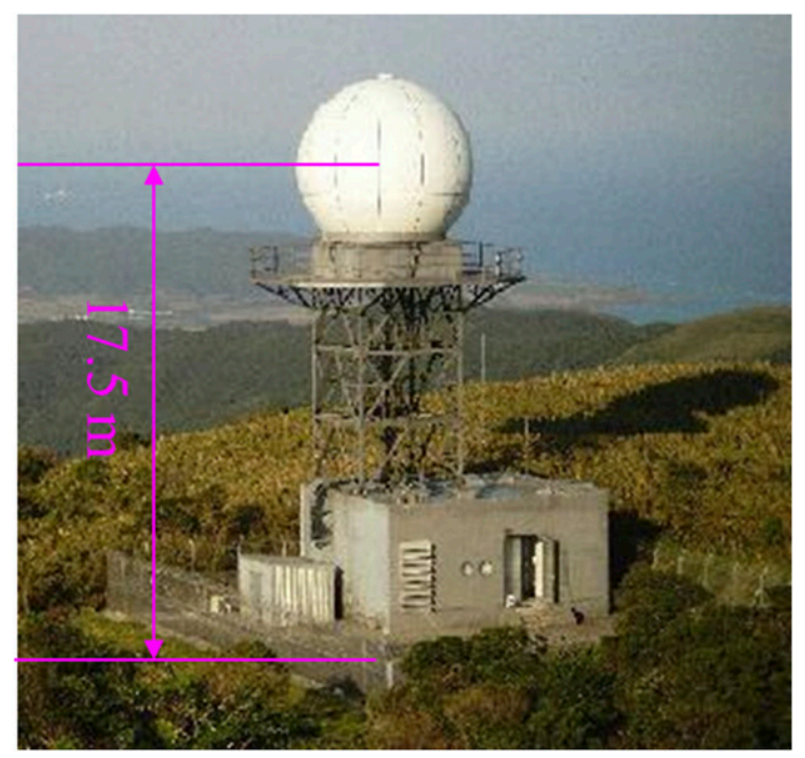

FIG. 19. Photo of the Ishigaki radar site (photo is from the JMA website https://www.jma-net.go.jp/ishigaki/know/bestshot/ bestshot.html). 
2015-0823-1225 UTC -0.10PPI

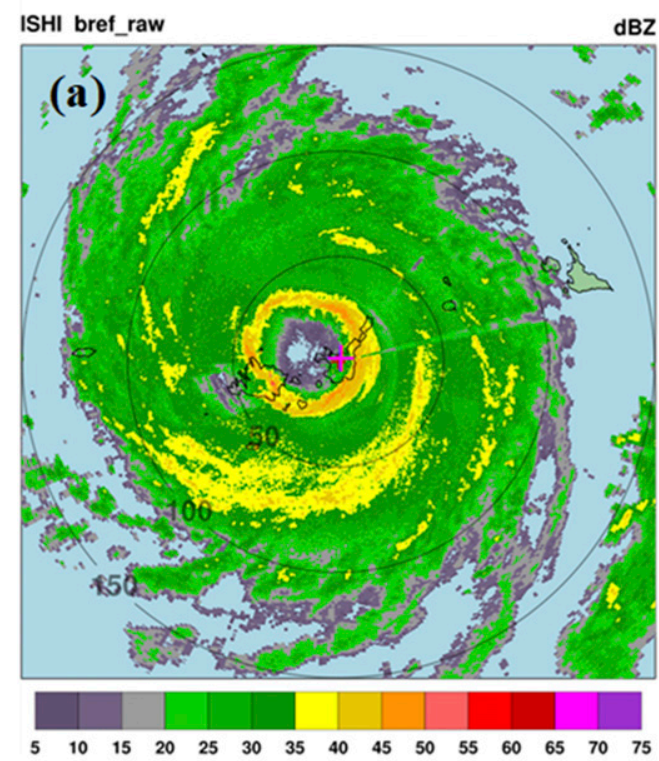

2015-0823-1225 UTC -0.10PPI

ISHI bref_simu

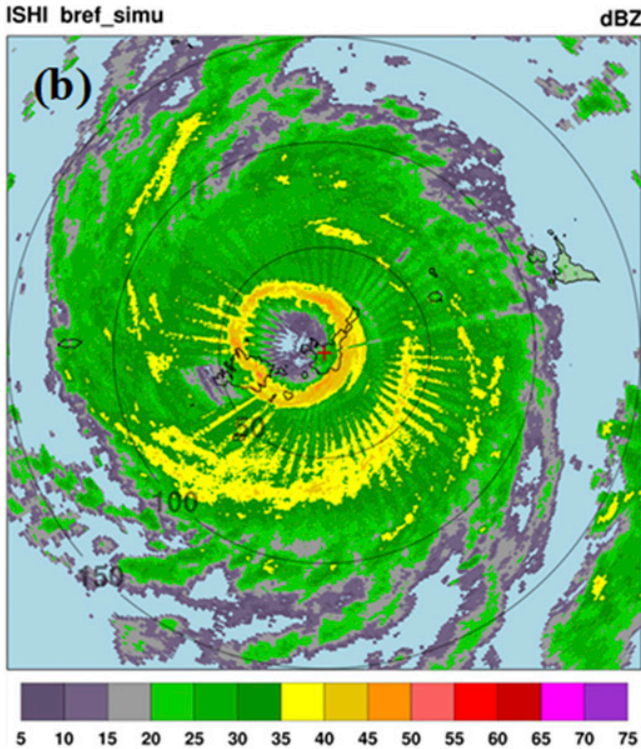

2015-0823-1225 UTC -0.10PPI

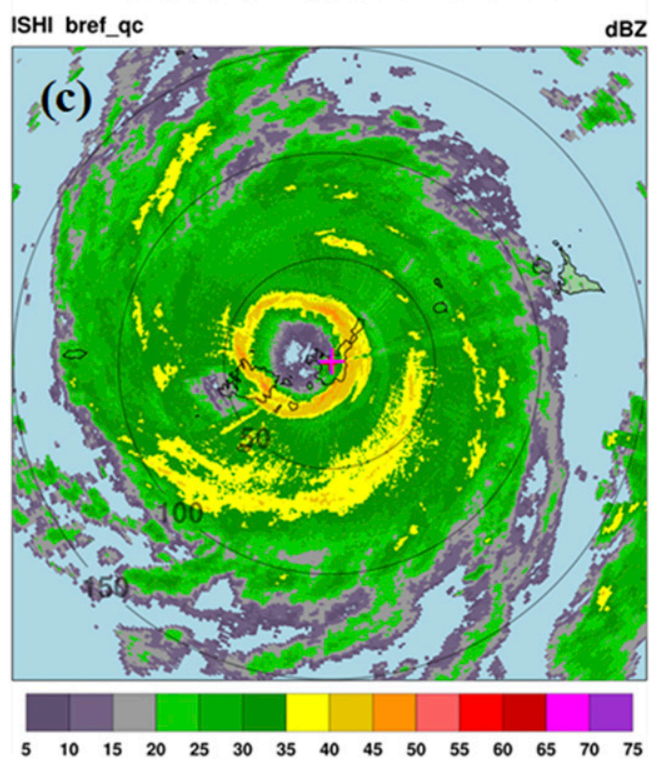

FIG. 20. (a) Reflectivity field at 1225 UTC at an elevation angle of $-0.1^{\circ}$ on 23 Aug 2015. (b) As in (a), but for the simulated reflectivity field. (c) As in (a), but for the reflectivity field after applying the bandpass filter QC procedure.

speeds from the Hualien weather station, which is approximately $2.1 \mathrm{~km}$ southwest of the radar site. Sustained wind speeds greater than $20 \mathrm{~m} \mathrm{~s}^{-1}$ occur within a 1-h time window centered at approximately 2245 UTC 17 July, and the maximum sustained wind speed is $28.2 \mathrm{~m} \mathrm{~s}^{-1}$. Hourly maximum gust wind speeds greater than $30 \mathrm{~m} \mathrm{~s}^{-1}$ occur at 2200, 2245, and 2302 UTC, with wind speeds of $38.9,58.5$, and $46.2 \mathrm{~m} \mathrm{~s}^{-1}$, respectively. Reflectivity oscillation signals are found at 2226 and 2236 UTC, 10-20 min earlier than the occurrence of the maximum hourly gust wind speed with a value of $58.5 \mathrm{~m} \mathrm{~s}^{-1}$. Furthermore, a VAD wind analysis is conducted to estimate the wind speeds from the radar observations. Because electromagnetic waves were not transmitted at low to middle elevations, an elevation angle of $14.6^{\circ}$ and a nearest range of $2.25 \mathrm{~km}$ are chosen for the VAD analysis. Figure 18 shows that the wind speeds determined from the VAD analysis are approximately $42 \mathrm{~m} \mathrm{~s}^{-1}$ at 2203 and 2213 UTC, and the wind speeds dramatically increase to $59 \mathrm{~m} \mathrm{~s}^{-1}$ at 2223 UTC and further increase to $62 \mathrm{~m} \mathrm{~s}^{-1}$ at 2233 UTC. Generally, the wind speeds from the VAD analysis are close to the surface gust wind speeds and are consistent with the occurrence times of the reflectivity oscillation 


\section{5-0823-1155 UTC -0.10PPI}

ISHI bref_qc

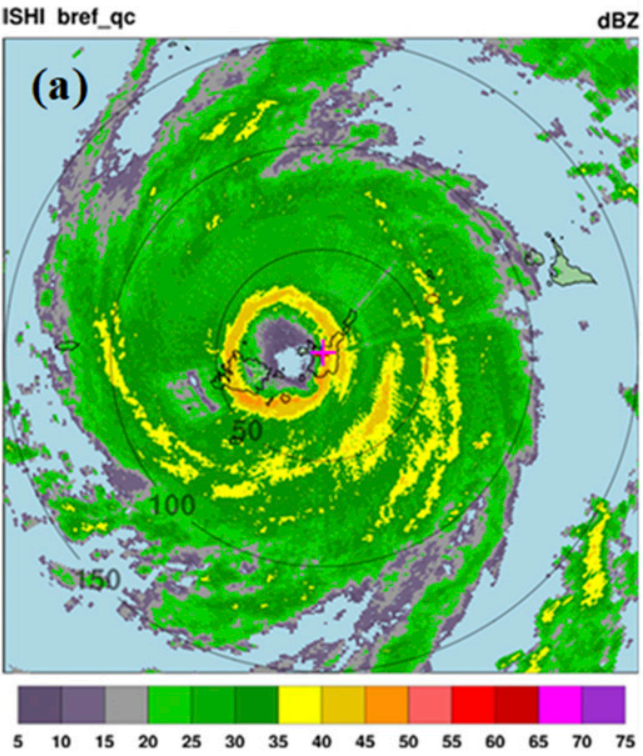

\section{5-0823-1155 UTC 0.20PPI}

ISHI bref_qc

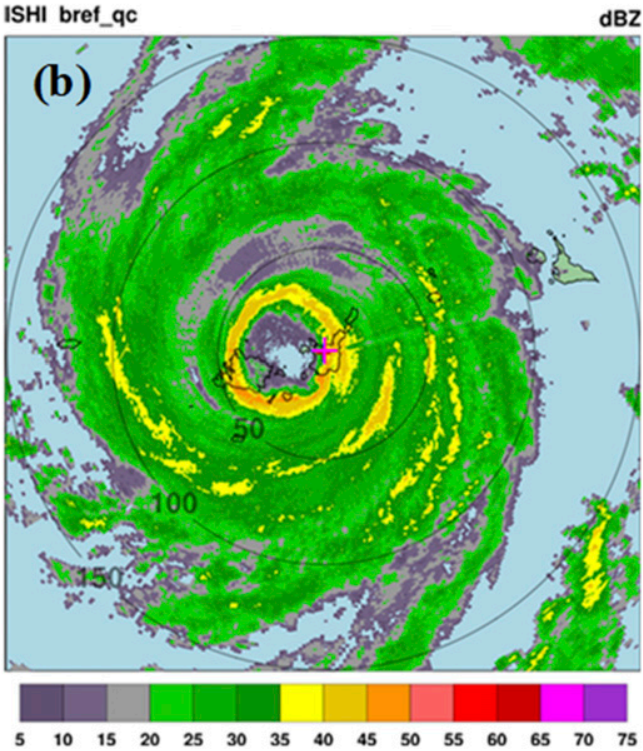

FIG. 21. Reflectivity field at 1155 UTC 23 Aug 2015 after applying the bandpass filter QC procedure at elevation angles of (a) $-0.1^{\circ}$ and (b) $0.2^{\circ}$.

signals (Figs. 16 and 18). Consequently, the threshold of gust winds for reflectivity oscillation signals is speculated to be between 38.9 and $58.5 \mathrm{~m} \mathrm{~s}^{-1}$ based on the surface observations and VAD analysis, and this range for the wind speed threshold is comparable to the aforementioned threshold of $45 \mathrm{~m} \mathrm{~s}^{-1}$ for Typhoon Goni (2015). However, the wind speed threshold required to trigger the vibrational effects of a radar tower must be further investigated and clarified by wind tunnel experiments (e.g., Li et al. 2017), as mentioned above.

\section{Discussion}

\section{a. Antenna oscillations}

According to the fundamental period of building vibration, the fundamental vibration period $T$ (s) for a building shorter than $50 \mathrm{~m}$ can be expressed by the following empirical formula (Xu et al. 2014):

$$
0.014 H \leq T \leq 0.025 H
$$

where $H(\mathrm{~m})$ is the height of the building, which is generally proportional to the fundamental period. The antenna height of the ISHI radar is $17.5 \mathrm{~m}$ (Fig. 19) above ground level (AGL), which is $12.5 \mathrm{~m}$ shorter than the height $(30 \mathrm{~m})$ of the RCHL radar. According to this empirical formula, the fundamental vibration periods are $0.25-0.44 \mathrm{~s}$ for the ISHI radar and $0.42-0.75 \mathrm{~s}$ for the RCHL radar, which are comparable to the predominant periods of the antenna oscillation signal for the ISHI radar $(0.21-0.38 \mathrm{~s})$ and reflectivity oscillation signal for the RCHL radar $(0.52-0.59 \mathrm{~s})$. These results essentially satisfy the expected wind-induced vibrations of buildings, illustrating that a taller tower corresponds to a longer vibration or oscillation period.
The maximum antenna oscillation amplitudes occur for elevation angles greater than approximately $0.2^{\circ}$ for wavenumbers $45-70$ between 1015 and 1215 UTC and between 1340 and 1430 UTC during Typhoon Goni; thus, the minimum wind speed threshold for antenna oscillation is approximately $45 \mathrm{~m} \mathrm{~s}^{-1}$. For Typhoon Haitang, the reflectivity oscillation phenomenon occurred at 2226 and 2236 UTC, approximately 10-20 min earlier than the hourly gust wind speed of $58.5 \mathrm{~m} \mathrm{~s}^{-1}$ at 2245 UTC. Before the reflectivity oscillation phenomenon occurred, the hourly gust wind speed had a value of $38.9 \mathrm{~m} \mathrm{~s}^{-1}$ at 2200 UTC. The wind speeds from the VAD analysis are close to the surface gust wind speeds and are consistent with the occurrence times of the reflectivity oscillation signals, as mentioned above. Consequently, the gust/VAD wind speed threshold for antenna oscillation is speculated to be greater than $45 \mathrm{~m} \mathrm{~s}^{-1}$ and $38.9-58.5 \mathrm{~m} \mathrm{~s}^{-1}$ for the ISHI and RCHL radars, respectively. The wind speed thresholds for antenna oscillations result from the effects of building vibrations, which are closely related to the structure, shape, material, height, and weight of the building (e.g., Xu et al. 2014; Shakya et al. 2016). These vibrational effects could be adequately mitigated if radar towers are designed similar to a tuned mass damper (TMD), such as those used for high-rise buildings, under extremely strong wind conditions (e.g., Tuan and Shang 2014).

\section{b. Oscillation simulation}

As shown in section $3 \mathrm{a}$, the radar tower oscillates for a maximum wind speed exceeding $45 \mathrm{~m} \mathrm{~s}^{-1}$, which results in antenna oscillations and subsequently influences the data quality of the radar observations. To further investigate this phenomenon, the influences of antenna oscillations on radar reflectivity are simulated. As documented in section 3a, the oscillation phenomenon disappeared when Typhoon Goni's 

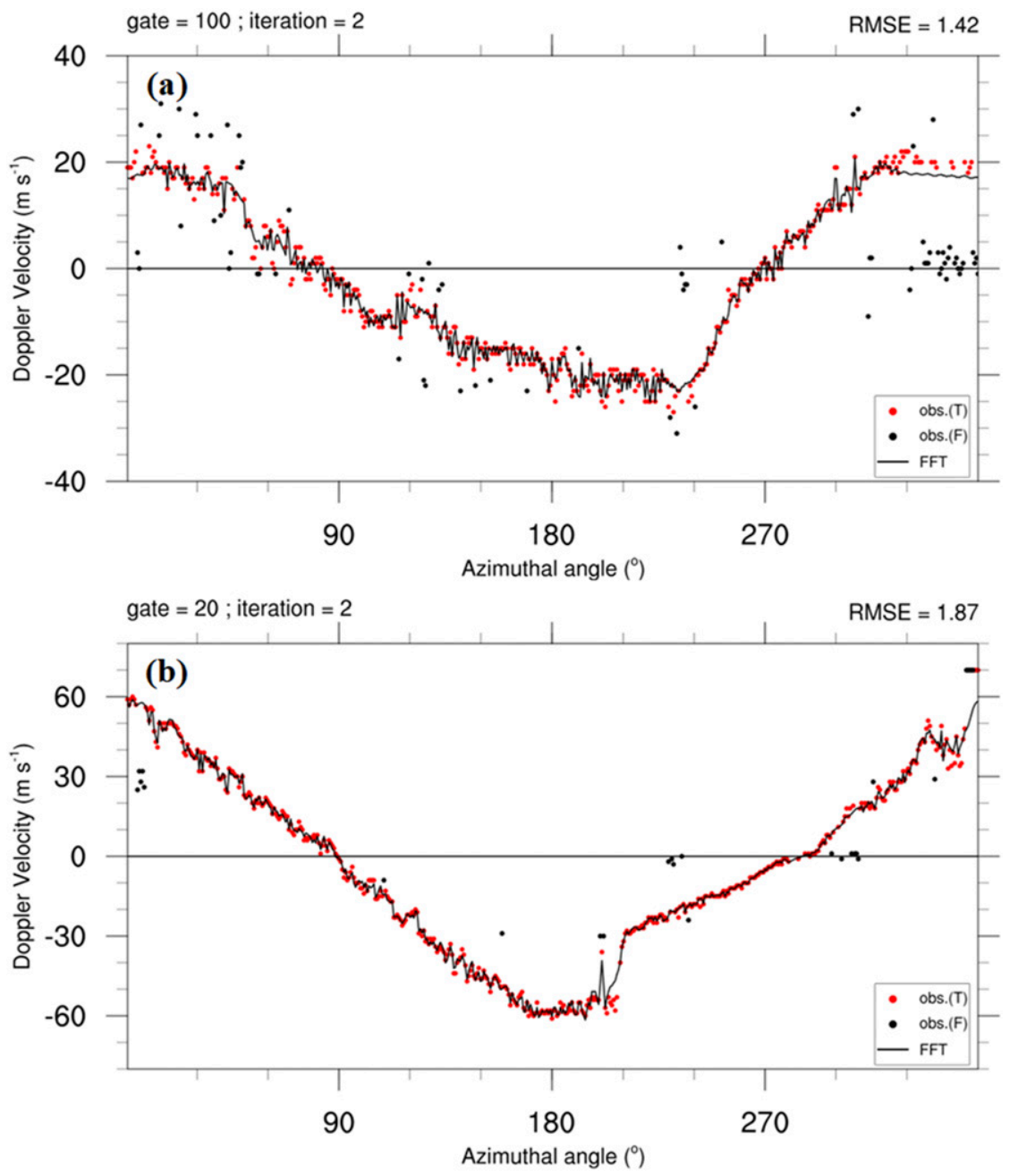

FIG. 22. VAD examples from ranges of (a) $50 \mathrm{~km}$ and (b) $10 \mathrm{~km}$ at 1155 UTC 23 Aug 2015. The black (red) dots indicate the data before (after) applying the bandpass filter QC procedure. The solid line indicates the fitted curve from the FFT analysis (see details in the text).

eye moved over the radar site because the wind speeds around the radar site decreased. To simulate the oscillation phenomenon, the reflectivity data at 1225 UTC at an elevation angle of $-0.1^{\circ}$ (Fig. 20a) are linearly interpolated from the reflectivity data observed at $-0.4^{\circ}$ and $0.2^{\circ}$ using elevations recorded at an elevation angle of $-0.1^{\circ}$ at $1155 \mathrm{UTC}$ (Fig. 3b). Figure $20 \mathrm{~b}$ presents the simulation result, which shows that oscillation signals are quite similar to those at 1155 UTC (Fig. 3b). Beam patterns with different amplitudes can also be adequately simulated, implying that the vertical gradient dominates the strength of the oscillation phenomenon, especially in regions with sea clutter.

\section{c. Mitigation of oscillation features}

As documented above, oscillation signals can be decomposed into a series of wavenumbers associated with given radii and elevations by using FFT analysis. To reduce the influences of antenna oscillations on radar observations, a QC procedure consisting of a bandpass filter is applied by filtering out the predominant wavenumbers (between 40 and 70 ) on individual rings for both the reflectivity and Doppler velocity fields. In addition, any ring containing $<256$ data points (half of the beam number) is not employed in the FFT analysis. To evaluate the performance of the proposed bandpass filter QC procedure, the simulated data are used to filter out the oscillation signals. Figure 20c shows the results after the QC procedure is applied, indicating that regular radial patterns are apparently mitigated and weather signals are retained compared with the original reflectivity field at 1225 UTC (Fig. 20a). However, high-frequency oscillation signals can still be found in the low-reflectivity and spiral rainband regions. Generally, the proposed bandpass filter QC procedure shows good performance and is adequate for mitigating oscillation signals in the reflectivity field.

Figure 21a shows the reflectivity field at an elevation angle of $-0.1^{\circ}$ at $1155 \mathrm{UTC}$ after implementing the proposed QC 


\section{ISHI bvel_vdaqc}

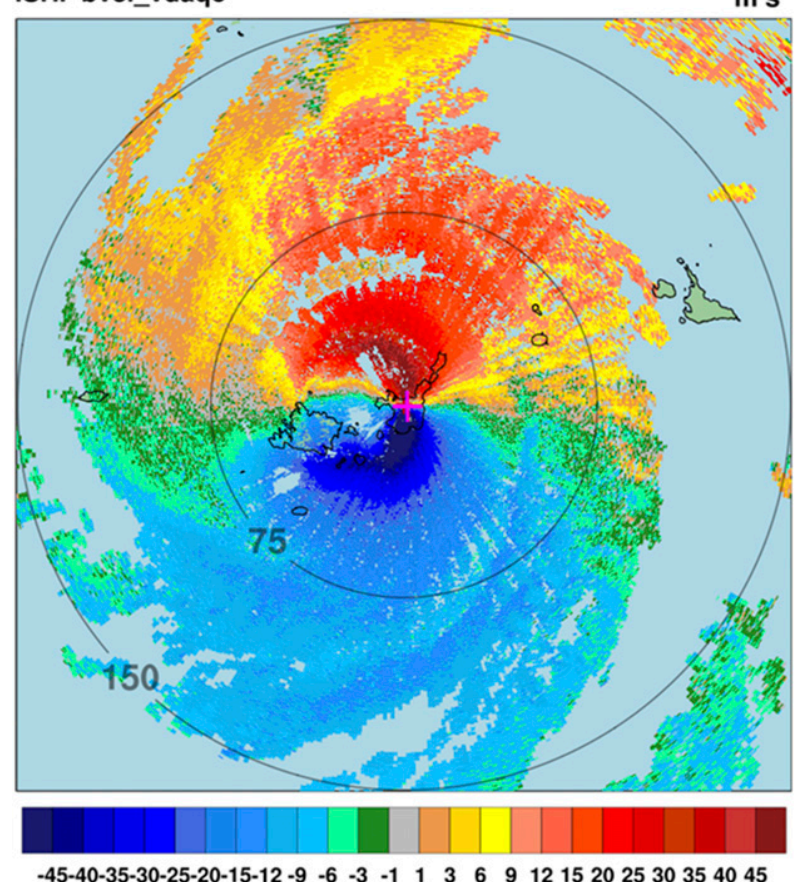

FIG. 23. Doppler velocity field at 1155 UTC 23 Aug 2015 after applying the bandpass filter QC procedure at an elevation angle of $0.2^{\circ}$.

procedure. Similar to the simulated reflectivity field shown above (Fig. 20b), the oscillation signals can be significantly mitigated, although weak oscillation signals remain near the low-reflectivity and spiral rainband regions. At a higher elevation angle of $0.2^{\circ}$, better performance is found in mitigating oscillation features after applying the QC procedure (Fig. 21b). This examination shows that the oscillation features in radar observations can be mitigated by filtering out wavenumbers 40-70 if the data coverage in the azimuthal direction at a constant range is sufficient for spectral analysis, such as FFT analysis. In general, these conditions were adequately satisfied during the antenna oscillation period when Typhoon Goni passed the ISHI radar site.

As mentioned above, the amplitudes of the oscillation signals in the Doppler velocity field are not comparable among different azimuths even though the winds are horizontally homogenous. In addition, the vertical gradient of the Doppler velocity field contributes to variations in the oscillation signals, as shown in the reflectivity field. Therefore, the QC issue in the Doppler velocity field is more complicated than that in the reflectivity field, and thus, two steps are conducted. The first step is to use a fitting curve as a reference to remove extremely unreasonable data, that is, when the fitting curve is composed of low wavenumbers $<6$. The raw data are labeled if the differences between the data values and fitted curve values are greater than $25 \%$ of the fitted curve values, with a minimum criterion of $5 \mathrm{~m} \mathrm{~s}^{-1}$. The second step is to recalculate a new fitted curve from the nonlabeled data without wavenumbers between 40 and 70 .
Then, the same QC criteria employed in the first step are also applied in the second step to remove unreasonable data from the raw data.

Figure 22a shows a VAD analysis example for a range of $50 \mathrm{~km}$ at $1155 \mathrm{UTC}$, showing that the maximum and minimum Doppler velocity is close to 30 and $-30 \mathrm{~m} \mathrm{~s}^{-1}$, respectively, and that data points near azimuths between $300^{\circ}$ and $360^{\circ}$ substantially deviate from the fitted line; these discontinuous data are close to the zero value that results from sea clutter signals. For the data across the eyewall region at a radius of $10 \mathrm{~km}$ (Fig. 22b), the maximum and minimum Doppler velocity values (nearly 60 and $-60 \mathrm{~m} \mathrm{~s}^{-1}$, respectively) are twice those at a radius of $50 \mathrm{~km}$. In addition, the distribution of Doppler velocities fluctuates less than that at a radius of $50 \mathrm{~km}$, possibly due to the lower influence of sea clutter signals. Similar to the result at a radius of $50 \mathrm{~km}$, a reasonable data distribution is obtained after implementing the two-step QC procedure. PPI Doppler velocity data are used to evaluate the performance in removing unreasonable data in two dimensions. Figure 23 shows the results at a PPI of $0.2^{\circ}$ at 1155 UTC obtained by using the two-step QC algorithm. Most beam patterns in the Doppler velocity field can be properly eliminated compared with the data before implementing the QC procedure (Fig. 5b), indicating that the QC algorithm can potentially reduce the influences resulting from antenna oscillations. However, it is very challenging if strong gradients in the Doppler velocities exist, especially for small-scale vortices (e.g., Wurman and Kosiba 2018; Fernández-Cabán et al. 2019; Alford et al. 2019). The above QC problem could be mitigated if the signatures associated with mesocyclones and mesovortices can be detected by the algorithm known as the Mesocyclone Detection Algorithm (MDA; Stumpf et al. 1998) prior to the algorithm proposed in this study being applied.

\section{Conclusions}

This study investigates the antenna oscillation phenomena caused by extremely strong wind speeds produced within Typhoon Goni's eyewall that encompassed Ishigaki Island. The ISHI C-band Doppler radar operated by the JMA is used to investigate the influences of extremely strong wind speeds on reflectivity and Doppler velocity fields. The radar hardware recorded antenna elevation angle oscillations with a maximum amplitude of $\sim 0.2^{\circ}$ at a $0.2^{\circ}$ elevation angle at 1155 UTC 23 August 2015. The corresponding reflectivity intensities present high-frequency oscillations with a maximum amplitude of $16 \mathrm{~dB}$. Via FFT analysis, the predominant oscillation period is calculated as approximately $0.25-0.33 \mathrm{~s}$. Additionally, two antenna oscillation periods are found; between these two oscillation periods, the oscillation phenomenon disappeared with decreasing wind speed when Typhoon Goni's eye moved over the radar site. Moreover, maximum amplitudes of elevation angle oscillations greater than approximately $0.02^{\circ}$ for wavenumbers $45-70$ are found between 0955 and 1205 UTC and between 1335 and 1445 UTC during Typhoon Goni's passage. The wind speeds estimated from VAD analysis at a range of $1 \mathrm{~km}$ for the two antenna oscillation 
periods are greater than $45 \mathrm{~m} \mathrm{~s}^{-1}$, with a maximum value of approximately $70 \mathrm{~m} \mathrm{~s}^{-1}$. The surface station on Ishigaki Island also observed a maximum gust wind speed of $71 \mathrm{~m} \mathrm{~s}^{-1}$. Although the wind speed estimations and observations differ with regard to both altitude and instrumentation, the temporal evolutions of the wind speeds are similar except for the period when Typhoon Goni's eye moved over the radar site. The large differences during the passage of Typhoon Goni's eye could have been contributed by differences in the horizontal and vertical wind structures of the typhoon circulation.

Regarding the reflectivity oscillation signal, the antenna oscillations are approximately $180^{\circ}$ out of phase and generally consistent with the vertical gradient of reflectivity. The Doppler velocity field is also influenced by the antenna oscillations, although the oscillation signals are relatively less pronounced since the oscillation signals are also a function of the wind direction and radar azimuth in addition to the vertical gradient. To further investigate this phenomenon, the influences of antenna oscillations on radar reflectivity are simulated. Beam patterns with different amplitudes can also be adequately simulated, implying that the vertical gradient dominates the strength of the oscillation phenomenon, especially in regions with sea clutter.

A similar oscillation phenomenon is also found in observations at the RCHL radar site when the eyewall of Typhoon Haitang (2005) affected eastern Taiwan with an hourly maximum gust wind speed of $58.5 \mathrm{~m} \mathrm{~s}^{-1}$. The estimated threshold for the occurrence of the reflectivity oscillation signal is between 38.9 and $58.5 \mathrm{~m} \mathrm{~s}^{-1}$ from the surface observations and VAD analysis, which is comparable to the wind speed threshold of $45 \mathrm{~m} \mathrm{~s}^{-1}$ estimated for Typhoon Goni (2015) based on the ISHI radar data.

To reduce the influences of antenna oscillations on radar observations, a bandpass filter QC procedure is applied by filtering out the predominant wavenumbers (between 40 and 70) on individual rings for both the reflectivity field and the Doppler velocity field. As a consequence, oscillation signals can be significantly mitigated, although weak oscillation signals remain near the low-reflectivity and spiral rainband regions. The QC issue in the Doppler velocity field is more complicated than that in the reflectivity field, and thus, a two-step procedure is conducted. Most beam patterns in the Doppler velocity field can be properly eliminated compared with the data before the implementation of the QC procedure (Fig. 5b), indicating that the QC algorithm can potentially reduce the influences from antenna oscillations.

The estimated fundamental vibration periods are comparable to the predominant periods analyzed based on reflectivity observations, with values of 0.33 and $0.5 \mathrm{~s}$. The results are essentially consistent with the expected wind-induced vibrations of buildings, which could be adequately mitigated if extremely strong wind conditions are considered in the design of radar towers. Detailed oscillation simulations are suggested for future research, such as wind tunnel tests and associated analyses, to provide solutions for mitigating the vibrational effects of radar towers under extremely strong wind conditions.

Acknowledgments. The authors thank the Japan Meteorological Agency and Central Weather Bureau in Taiwan for providing the radar and weather station data. The authors are also grateful to three anonymous reviewers for their insightful comments and suggestions. This research is supported by the Ministry of Science and Technology of Taiwan, Republic of China, under Grants 107-2625-M-052-001 and 108-2625-M-052-002.

\section{REFERENCES}

Alford, A. A., M. I. Biggerstaff, G. D. Carrie, J. L. Schroeder, B. D. Hirth, and S. M. Waugh, 2019: Near-surface maximum winds during the landfall of Hurricane Harvey. Geophys. Res. Lett., 46, 973-982, https://doi.org/10.1029/2018GL080013.

Browning, K. A., and R. Wexler, 1968: The determination of kinematic properties of a wind field using Doppler radar. J. Appl. Meteor., 7, 105-113, https://doi.org/10.1175/15200450(1968)007<0105:TDOKPO>2.0.CO;2.

Chang, C.-P., T.-C. Yeh, and J. M. Chen, 1993: Effects of terrain on the surface structure of typhoons over Taiwan. Mon. Wea. Rev., 121, 734-752, https://doi.org/10.1175/1520-0493(1993) $121<0734$ :EOTOTS $>2.0$. CO;2.

Chang, P.-L., P.-F. Lin, B. J.-D. Jou, and J. Zhang, 2009: An application of reflectivity climatology in constructing radar hybrid scans over complex terrains. J. Atmos. Oceanic Technol., 26, 1315-1327, https://doi.org/10.1175/2009JTECHA1162.1.

—, W.-T. Fang, P.-F. Lin, and M.-J. Yang, 2019: A vortex-based Doppler velocity dealiasing algorithm for tropical cyclones. J. Atmos. Oceanic Technol., 36, 1521-1545, https://doi.org/ 10.1175/JTECH-D-18-0139.1.

Collier, C. G., 1998: Observations of sea clutter using an S-band weather radar. Meteor. Appl., 5, 263-270, https://doi.org/ 10.1017/S1350482798000930.

Dazhang, T., S. G. Geotis, R. E. Passarelli Jr., A. L. Hansen, and C. L. Frush, 1984: Evaluation of an alternating-PRF method for extending the range of unambiguous Doppler velocity. Preprints, 22nd Conf. on Radar Meteorology, Zurich, Switzerland, Amer. Meteor. Soc., 523-527.

Donaldson, R. J., Jr., 1991: A proposed technique for diagnosis by radar of hurricane structure. J. Appl. Meteor., 30, 1636-1645, https://doi.org/10.1175/1520-0450(1991)030<1636:APTFDB > 2.0.CO;2.

— , and F. I. Harris, 1989: Estimation by Doppler radar of curvature, diffluence, and shear in cyclonic flow. J. Atmos. Oceanic Technol., 6, 26-35, https://doi.org/10.1175/1520-0426(1989) $006<0026$ :EBDROC $>2.0 . \mathrm{CO} ; 2$.

Fernández-Cabán, P. L., and Coauthors, 2019: Observing Hurricane Harvey's eyewall at landfall. Bull. Amer. Meteor. Soc., 100, 759775, https://doi.org/10.1175/BAMS-D-17-0237.1.

Frush, C. L., 1991: A graphical representation of the radar velocity dealiasing problem. Preprints, 25th Int. Conf. on Radar Meteoroloy, Paris, France, Amer. Meteor. Soc., 885-888.

Garcia-Rivera, J. M., 2018: Hurricane Maria in Puerto Rico: Structure and intensity evolution prior to landfall. 33rd Conf. on Hurricanes and Tropical Meteorology, Ponte Vedra, FL, Amer. Meteor. Soc., 72, https://ams.confex.com/ ams/33HURRICANE/webprogram/Paper344113.html.

Hayes, P. D., 2011: Determining surface winds from Doppler radar data during hurricane passages over Florida. Ph.D. dissertation, Florida State University, 59 pp., http://purl.flvc.org/fsu/ fd/FSU_migr_etd-4186.

Hazelton, A. T., and R. E. Hart, 2013: Hurricane eyewall slope as determined from airborne radar reflectivity data: Composites and case studies. Wea. Forecasting, 28, 368-386, https:// doi.org/10.1175/WAF-D-12-00037.1.

Heideman, M. T., D. H. Johnson, and C. S. Burrus, 1985: Gauss and the history of the fast Fourier transform. Arch. Hist. Exact Sci., 34, 265-277, https://doi.org/10.1007/BF00348431. 
Jian, G.-J., and C.-C. Wu, 2008: A numerical study of the track deflection of Supertyphoon Haitang (2005) prior to its landfall in Taiwan. Mon. Wea. Rev., 136, 598-615, https://doi.org/ 10.1175/2007MWR2134.1.

Johnson, J. T., P. L. MacKeen, A. Witt, E. D. W. Mitchell, G. J. Stumpf, M. D. Eilts, and K. W. Thomas, 1998: The storm cell identification and tracking algorithm: An enhanced WSR-88D algorithm. Wea. Forecasting, 13, 263-276, https://doi.org/ 10.1175/1520-0434(1998)013<0263:TSCIAT>2.0.CO;2.

Jorgensen, D. F., 1984: Mesoscale and convective-scale characteristics of mature hurricanes. Part I: General observations by research aircraft. J. Atmos. Sci., 41, 1268-1286, https://doi.org/ 10.1175/1520-0469(1984)041<1268:MACSCO > 2.0.CO;2.

Kossin, J. P., and W. H. Schubert, 2001: Mesovortices, polygonal flow patterns, and rapid pressure falls in hurricane-like vortices. J. Atmos. Sci., 58, 2196-2209, https://doi.org/10.1175/15200469(2001)058<2196:MPFPAR >2.0.CO;2.

Kuo, H. C., R. T. Williams, and J. H. Chen, 1999: A possible mechanism for the eye rotation of Typhoon Herb. J. Atmos. Sci., 56, 1659-1673, https://doi.org/10.1175/1520-0469(1999) 056<1659:APMFTE $>2.0 . \mathrm{CO} ; 2$.

Lee, W.-C., and F. D. Marks Jr., 2000: Tropical cyclone kinematic structure retrieved from single-Doppler radar observations. Part II: The GBVTD-simplex center finding algorithm. Mon. Wea. Rev., 128, 1925-1936, https://doi.org/10.1175/15200493(2000)128<1925:TCKSRF $>2.0$. CO $; 2$.

- B. J.-D. Jou, P.-L. Chang, and S.-M. Deng, 1999: Tropical cyclone kinematic structure retrieved from single-Doppler radar observations. Part I: Interpretation of Doppler velocity patterns and the GBVTD technique. Mon. Wea. Rev., 127, 2419-2439, https://doi.org/10.1175/1520-0493(1999)127<2419: TCKSRF $>2.0 . \mathrm{CO} ; 2$.

Lhermitte, R. M., and D. Atlas, 1961: Precipitation motion by pulse Doppler. Proc. Ninth Weather Radar Conf., Kansas City, MO, Amer. Meteor. Soc., 218-223.

Li, Q. S., X. Li, Y. He, and J. Yi, 2017: Observation of wind fields over different terrains and wind effects on a super-tall building during a severe typhoon and verification of wind tunnel predictions. J. Wind Eng. Ind. Aerodyn., 162, 73-84, https:// doi.org/10.1016/j.jweia.2017.01.008.

Li, Y., X. Wang, and M. Xue, 2012: Assimilation of radar radial velocity data with the WRF hybrid ensemble-3DVAR system for the prediction of hurricane Ike (2008). Mon. Wea. Rev., 140, 3507-3524, https://doi.org/10.1175/MWR-D-12-00043.1.

Lin, Y.-L., N. C. Witcraft, and Y.-H. Kuo, 2006: Dynamics of track deflection associated with the passage of tropical cyclones over a mesoscale mountain. Mon. Wea. Rev., 134, 3509-3538, https://doi.org/10.1175/MWR3263.1.

Marks, F. D., and R. A. Houze, 1987: Inner core structure of Hurricane Alicia from airborne Doppler radar observations. J. Atmos. Sci., 44, 1296-1317, https://doi.org/10.1175/15200469(1987)044<1296:ICSOHA > 2.0.CO;2.

Miller, M. A., J. Verlinde, C. V. Gilbert, G. J. Lehenbauer, J. S. Tongue, and E. E. Clothiaux, 1998: Detection of nonprecipitating clouds with the WSR-88D: A theoretical and experimental survey of capabilities and limitations. Wea. Forecasting, 13, 1046-1062, https://doi.org/10.1175/15200434(1998)013<1046:DONCWT>2.0.CO;2.

Monin, A. S., and A. M. Obukhov, 1954: Basic regularity in turbulent mixing in the surface layer of the atmosphere. Akad. Nauk. S.S.S.R. Trud. Geofiz. Inst., 24, 151.

Osuri, K. K., U. C. Mohanty, A. Routray, and D. Niyogi, 2015: Improved prediction of Bay of Bengal tropical cyclones through assimilation of Doppler weather radar observations. Mon. Wea. Rev., 143, 4533-4560, https://doi.org/10.1175/ MWR-D-13-00381.1.

Ryzhkov, A. V., P. Zhang, R. Doviak, and C. Kessinger, 2002: Discrimination between weather and sea clutter using Doppler and dual-polarization weather radars. Proc. 27th General Assembly of the Int. Union of Radio Science, Maastricht, Netherlands, International Union of Radio Science, F1.P.3, http://www.ursi.org/Proceedings/ProcGA02/papers/p1383.pdf.

Shakya, M., H. Varum, R. Vicente, and A. Costa, 2016: Empirical formulation for estimating the fundamental frequency of slender masonry structures. Int. J. Archit. Heritage, 10, 55-66, https://doi.org/10.1080/15583058.2014.951796.

Shimada, U., M. Sawada, and H. Yamada, 2018: Doppler radar analysis of the rapid intensification of Typhoon Goni (2015) after eyewall replacement. J. Atmos. Sci., 75, 143-162, https:// doi.org/10.1175/JAS-D-17-0042.1.

Stumpf, G., A. Witt, E. D. Mitchell, P. Spencer, J. Johnson, M. Eilts, K. Thomas, and D. Burgess, 1998: The National Severe Storms Laboratory mesocyclone detection algorithm for the WSR88D. Wea. Forecasting, 13, 304-326, https://doi.org/10.1175/ 1520-0434(1998)013<0304:TNSSLM>2.0.CO;2.

Tamura, Y., K. Shimada, and K. Hibi, 1993: Wind response of a tower (Typhoon observation at the Nagasaki Huis Ten Bosch Domtoren). J. Wind Eng. Ind. Aerodyn., 50, 309-318, https:// doi.org/10.1016/0167-6105(93)90086-4.

Tuan, A.-Y., and G.-Q. Shang, 2014: Vibration control in a 101storey building using a tuned mass damper. J. Appl. Sci. Eng., 17, 141-156, https://doi.org/10.6180/jase.2014.17.2.05.

Velden, C., T. Olander, D. Herndon, and J. P. Kossin, 2017: Reprocessing the most intense historical tropical cyclones in the satellite era using the advanced Dvorak technique. Mon. Wea. Rev., 145, 971-983, https://doi.org/10.1175/MWR-D-16-0312.1.

Wang, H., J. Sun, S. Fan, and X.-Y. Huang, 2013: Indirect assimilation of radar reflectivity with WRF 3D-Var and its impact on prediction of four summertime convective events. J. Appl. Meteor. Climatol., 52, 889-902, https://doi.org/10.1175/JAMC-D-12-0120.1.

Warde, D. A., and S. M. Torres, 2017: Staggered-PRT sequences for Doppler weather radars. Part II: Ground clutter mitigation on the NEXRAD network using the CLEAN-AP filter. J. Atmos. Oceanic Technol., 34, 703-716, https://doi.org/ 10.1175/JTECH-D-16-0072.1.

Wood, V. T., and R. A. Brown, 1992: Effects of radar proximity on single-Doppler velocity signatures of axisymmetric rotation and divergence. Mon. Wea. Rev., 120, 2798-2807, https://doi.org/ 10.1175/1520-0493(1992)120<2798:EORPOS > 2.0.CO;2.

Wu, C.-C., T.-H. Yen, Y.-H. Kuo, and W. Wang, 2002: Rainfall simulation associated with Typhoon Herb (1996) near Taiwan. Part I: The topographic effect. Wea. Forecasting, 17, 1001-1015, https://doi.org/10.1175/1520-0434(2003)017<1001: RSAWTH $>2.0 . \mathrm{CO} ; 2$.

Wurman, J., and K. Kosiba, 2018: The role of small-scale vortices in enhancing surface winds and damage in Hurricane Harvey (2017). Mon. Wea. Rev., 146, 713-722, https://doi.org/10.1175/ MWR-D-17-0327.1.

Xu, P., C. Xiao, and J. Li, 2014: Research on relationship between natural vibration periods and structural heights for high-rise buildings and its reference range in China. Int. J. High-Rise Build., 3, 49-64.

Yang, B., Y. Wang, and B. Wang, 2007: The effect of internally generated inner-core asymmetries on tropical cyclone potential intensity. J. Atmos. Sci., 64, 1165-1188, https://doi.org/ 10.1175/JAS3971.1. 